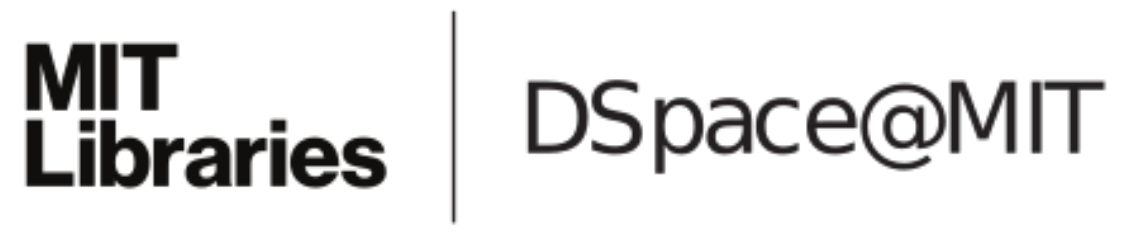

\author{
MIT Open Access Articles
}

\section{An Experimental and Modeling Study of Vacuum Residue Upgrading in Supercritical Water}

The MIT Faculty has made this article openly available. Please share how this access benefits you. Your story matters.

Citation: Gudiyella, Soumya, et al. “An Experimental and Modeling Study of Vacuum Residue Upgrading in Supercritical Water." AIChE Journal, Feb. 2018.

As Published: http://dx.doi.org/10.1002/aic.16131

Publisher: Wiley Blackwell

Persistent URL: http://hdl.handle.net/1721.1/113861

Version: Author's final manuscript: final author's manuscript post peer review, without publisher's formatting or copy editing

Terms of use: Creative Commons Attribution-Noncommercial-Share Alike 


\section{An Experimental and Modeling Study of Vacuum Residue Upgrading in Supercritical Water}

Soumya Gudiyella ${ }^{a}$, Lawrence Lai $^{a}$, Isaiah H. Borne ${ }^{a}$, Geoffrey A. Tompsett ${ }^{b}$, Michael T. Timko , $^{b}$ Ki-Hyouk Choi ${ }^{c}$, Mohnnad H. Alabsic, William H. Green ${ }^{a^{*}}$

a Department of Chemical Engineering, Massachusetts Institute of Technology, 77 Massachusetts Avenue, Cambridge, MA 02139

bepartment of Chemical Engineering, Worcester Polytechnic Institute, 100 Institute Rd, Worcester, MA 01609

${ }^{\mathrm{c}} \mathrm{R} \& D$ Center, Saudi Aramco, PO Box 62, Dhahran 31311, Saudi Arabia

*Corresponding author: whgreen@mit.edu

ABSTRACT: Arabian Heavy crude oil was fractionated into distillate and vacuum residue fractions. The vacuum residue fraction was treated with supercritical water (SCW) at $450{ }^{\circ} \mathrm{C}$ in a batch reactor for 15 to 90 minutes. The main products were gas, coke, and upgraded vacuum residue; the upgraded residue consisted of gasoline, diesel, and vacuum gas oil range components. The molecular composition of gas and upgraded vacuum residue was analyzed using gas chromatography (GC, GC×GC). SCW treatment converted higher carbon number aliphatics $(\geq$ $\mathrm{C}_{21}$ ) and long chain $\left(\geq \mathrm{C}_{5}\right)$ alkyl aromatic compounds into $\mathrm{C}_{1}-\mathrm{C}_{20}$ aliphatics, $\mathrm{C}_{1}-\mathrm{C}_{10}$ alkylaromatics and multi-ringed species. The concentrations of gasoline and diesel range compounds were greater in the upgraded product, compared to the feed. A first-order, five lump reaction network was developed to fit the yields of gas, coke, diesel and gasoline range components obtained from SCW upgrading of vacuum residue. Distillation of crude oil followed by SCW treatment of the heavy fraction approximately doubled the yield of chemicals, gasoline, and diesel, while forming significantly less coke than conventional upgrading methods.

** Many of the results in this manuscript were presented by S. Gudiyella at the 2016 AIChE Annual Meeting, identified as the Best Presentation in the session "Reaction Engineering of Biomass and Hydrocarbons in Supercritical Water” by the Session Chair K. Choi. 
KEYWORDS: Supercritical processes, chromatography, petroleum, reaction kinetics, hydrocarbons processing

\section{INTRODUCTION}

Global energy consumption is increasing; petroleum demand has grown by approximately 1.2\% per year since $2004 .{ }^{1}$ The growing demand for fuels has outstripped the rate of new discoveries of conventional crude oil. ${ }^{2}$ Growing petroleum demand motivates commercial interest to utilize heavy oils containing high amounts of heavy hydrocarbons and high concentration of heteroatoms (N, S, V, Ni etc.) as feedstocks to produce lighter fuels and chemicals. ${ }^{3}$ To maximize the yield of the required lighter fuels and chemicals, and to meet environmental regulations, heavy crude oils must be treated to remove heteroatoms and to convert heavy fractions into lighter, more desirable products that are compatible with modern combustion engines or suitable as chemical precursors.

Conventional techniques for crude oil upgrading include catalytic hydrotreating methods and thermal methods such as delayed coking and visbreaking. ${ }^{4-5} \mathrm{~A}$ drawback of catalytic hydrogenation is the requirement of large amounts of hydrogen gas, which is expensive $e^{4-5}$ and environmentally disadvantageous. ${ }^{6-7}$. During catalytic hydrogenation, the catalyst may be poisoned or coked and must be regenerated periodically, thereby increasing the cost. ${ }^{5}$ On the other hand, thermal methods reject valuable carbon as coke, a relatively low-value byproduct. Thermal methods are also not efficient in removing impurities such as sulfur and nitrogen. ${ }^{4}$

Crude oil upgrading with supercritical water (SCW) is an effective technique for converting heavy feedstocks into lighter hydrocarbons and for removing sulfur impurities. ${ }^{5,8-12}$ The SCW upgrading method does not require hydrogen and also minimizes coke formation when compared to dry thermal methods. Water has unique properties at supercritical conditions, which 
makes it a suitable solvent for the upgrading process. Above its critical point, the dielectric constant of water is similar to an organic solvent, which promotes its miscibility with organic compounds, ${ }^{5}$ helping to avoid phase separation that may lead to coke formation. Furthermore, water itself can act either as a catalyst or reactant, reducing the hydrogen requirement of downstream processes. ${ }^{13}$

Previous studies ${ }^{5,8-23}$ have established the potential of SCW treatment to upgrade model compounds and fractions of crude oil. When it comes to crude oil, most literature studies report the effects of SCW treatment on the bulk properties ${ }^{14-15,18}$ and only a few studies describe changes at the molecular level. ${ }^{11-12}$ Studies that combine both molecular level detail and bulk properties are required to understand the underlying chemical mechanisms. ${ }^{11}$ Previous work ${ }^{11}$ from our group used 2-dimensional gas chromatography $(\mathrm{GC} \times \mathrm{GC})$ to show that heavy compounds in Arabian Heavy (AH) crude oil crack to form lighter aliphatic and aromatic hydrocarbons. The current study builds on that work, and determines the cracking behavior of crude oil at varied reaction times ( 0 to 90 minutes), and at molecular level using gas chromatography (GC and GC $\times$ GC). The detailed molecular data were used to group hydrocarbon products into gasoline $\left(\mathrm{C}_{1}-\mathrm{C}_{10}\right)$, diesel $\left(\mathrm{C}_{11}-\mathrm{C}_{23}\right)$ and atmospheric residue (AR) range ( $\left.\geq \mathrm{C}_{24}\right)$ groups. Additional group types were defined for coke and gas products. A 5-component lump kinetic model was developed to interpret observed yields of the gasoline, diesel, AR, gas, and coke.

In a petroleum refinery, the distillate fraction is recovered from crude oil through atmospheric and vacuum distillation, and the residues are upgraded to convert them into lighter products ${ }^{24-25}$. A similar methodology was adopted in this work. The crude oil was vacuum-distilled to obtain a distillate and a vacuum residue fraction. The vacuum residue was upgraded using water at supercritical conditions. 
This work focused on three objectives. The first objective was to provide time-dependent molecular data on vacuum residue reactivity and product state when treated with SCW. The second objective was to describe the upgrading mechanism that produced the observed product distribution. The third objective was to quantify the yields of lighter fuels and perform a kinetic evaluation of the experimental data. A minor focus of this work was to use the molecular level information and quantify the yields of specific high-value chemicals such as benzene, toluene, ethylbenzene, xylenes and alkenes. To meet these objectives, Arabian Heavy (AH) crude oil was vacuum distilled at $350{ }^{\circ} \mathrm{C}$ to obtain distillate (37 wt.\% yield) and vacuum residue fractions (63 wt. \% yield). The vacuum residue fraction was upgraded in a stainless steel batch reactor under SCW conditions $\left(450{ }^{\circ} \mathrm{C}\right.$ and $>30 \mathrm{MPa}$ ) and over a range of reaction times (15-90 minutes) to observe the time evolution of products. The molecular composition of the product mixtures was then determined using gas chromatography, using both ordinary GC and two dimension GC×GC.

\section{MATERIALS AND METHODS}

Materials and vacuum distillation

Arabian Heavy crude oil (AH) was provided by Saudi Aramco. The physical and chemical characteristics of AH crude oil are described in the literature. ${ }^{26}$ Deionized water, purified by a Millipore unit to an electrical resistance of $18 \mathrm{M} \Omega-\mathrm{cm}$, was used for all experiments. Ultra-high purity helium (99.999\%) obtained from Airgas was used to fill the reactor headspace and as a GC carrier gas. HPLC grade dichloromethane, obtained from Sigma Aldrich and with purity $\geq 99.9 \%$, was used as a solvent for cleaning the reactor. Carbon disulfide ( $\geq 99.9 \%$, Sigma Aldrich) and 3chlorothiophene (98\%, Sigma Aldrich) were used as diluent and external standard to prepare the samples for GC×GC. 
Figure 1 is a schematic representation of the entire experimental procedure. AH was vacuum-distilled in a lab-scale apparatus described previously ${ }^{10-11}$. The distillation was terminated when the temperature in the boiler reached $350{ }^{\circ} \mathrm{C}$. The distillate and vacuum residue fractions were collected and used for experiments (also shown in Figure 1).

Vacuum residue upgrading experiments

The vacuum residue fraction was treated in a batch reactor under SCW conditions. The experimental procedure is shown in Figure 1 (b) and (c). The 316 stainless steel tube used as a batch reactor (internal volume $-2.4 \mathrm{e}-5 \mathrm{~m}^{3}$ ) has been described in detail previously. ${ }^{9-11}$. The batch reactor has two arms; one arm was connected to the gas inlet/outlet valve and the other arm was connected to the pressure transducer (Omega Model MMA5.0KV5P4B0T4A6). The voltage of the pressure transducer is read in a National Instruments data acquisition box (NI USB-6210) and the signal is collected on Signal Express software. The reactant feed consisted of $2 \mathrm{~g}$ of vacuum residue and $4 \mathrm{~g}$ of water. After the reactants were loaded into the reactor, the reactor was sealed, purged multiple-times with helium to remove air, and pressurized to 3 MPa using helium. The sealed batch reactor was lowered into a Techne FB-05 fluidized sand bath held at $450{ }^{\circ} \mathrm{C}$. The experiments were performed at reaction times of 15, 30, 40, 60, 75 and 90 minutes, and a pressure of 35-38 MPa. The reaction time includes the reactor heat-up time of approximately 10 minutes. The batch reactor pressure profile for a representative run is shown in Section 1 of the supplementary information. Post-reaction, the batch reactor was quenched in a water bath.

Three product fractions i.e., organic liquids (upgraded oil and reactor residue), gas and coke were obtained from vacuum residue and SCW experiments. The mass fraction of each product fraction was determined using equation (1).

Mass fraction of product fraction $=\frac{\text { Mass of product }}{\text { Mass of vacuum residue feed }(2 \mathrm{~g})} \times 100 \%$ 
Greater than $85 \mathrm{wt} \%$ of the vacuum residue feed was recovered post-reaction. The $30 \mathrm{~min}$ run was repeated twice to check reproducibility. The mass fractions of organic liquids, gas, and coke measured in these two runs were within $3 \mathrm{wt} \%$ of one another. Reproducibility was also confirmed for specific chemical products including aliphatics ( $\pm 3 \mathrm{wt} \%$ ), alkylbenzenes ( $\pm 2 \mathrm{wt} \%$ ) and multi-ring aromatics $( \pm 0.5 \mathrm{wt} \%)$. The gravimetric recovery of water was greater than $90 \%$.

The gas phase product was collected in supel-inert multi-layer foil sampling bag and analyzed using GC-FID. The mass of organic liquids and coke was determined gravimetrically using a Mettler Toledo - XS204 - Analytical Balance.

The organic liquids obtained post-upgrading consisted of two types of oil products, termed upgraded oil and reactor residue. Upgraded oil was recovered as an aqueous emulsion when the contents of the reactor were initially poured into a centrifuge tube (shown in Figure 1 (b)). The upgraded oil and water in the emulsion were separated by centrifugation. The oil was pipetted from the top of the aqueous phase and collected into pre-weighed vials. Reactor residue is the oil product that remained stuck at the bottom of the reactor, along with coke after the emulsion was poured out. The mixture of reactor residue and coke was recovered from the reactor using about $150 \mathrm{~mL}$ of dichloromethane (shown in Figure 1 (c)). The solvent mixture consisting of dichloromethane, reactor residue and coke was filtered to remove coke, using VWR Grade 413 filter paper of 5.5 $\mathrm{cm}$ diameter and $5 \mu \mathrm{m}$ porosity. After separation of coke, dichloromethane was evaporated in a Heidolph G5 rotary evaporator to collect the liquid reactor residue.

GC $\times$ GC analysis showed similar composition between the upgraded oil and reactor residue, for a reaction time of 30 minutes (Figures S2 and S3 in supplementary information). Therefore, for all the other runs only the upgraded oil was analyzed using GC $\times$ GC and the GC $\times$ GC -quantifiable portion of upgraded oil and reactor residue were assumed to be identical. 
The overall GC carbon recovery and GC×GC observed mass fraction were determined using equations (2) and (3).

Overall GC carbon recovery $=\frac{\sum \text { Mass of hydrocarbon species in organic liquids and gas phase }}{\text { Mass of vacuum residue feed }(2 \mathrm{~g})} \times 100 \%$

GC $\times$ GC observed mass fraction $=\frac{\sum \text { Mass of hydrocarbon species in product oil }}{\text { Mass of product oil in GC-vial }} \times 100 \%$

The GC $\times$ GC quantified species in the feed and organic liquids were categorized into gasoline and diesel lumps. The carbon number distributions in gasoline and diesel fuels were obtained from the literature. ${ }^{27-28}$. The gasoline fraction is the sum of $\mathrm{C}_{5}-\mathrm{C}_{10}$ components; diesel is the sum of $\mathrm{C}_{11}-\mathrm{C}_{23}$ compounds. The other product lumps were gas, coke and vacuum gas oil. The gas yields were quantified using GC-FID and the mass of coke was obtained through gravimetric analysis. GC $\times \mathrm{GC}$ was able to quantify species with carbon numbers up to 40 . The AR fraction is the sum of components with carbon number $\geq 24$. The GC unquantifiable mass fraction in the feed and the product oil was assumed to have carbon number $>40$ and the GC unquantifiable mass fraction was added to AR mass fraction.

$A R=(\Sigma G C \times G C$ quantified species with carbon number $\geq 24+$

GC unquantified mass fraction - coke )x $100 \%$

Proton NMR analysis of the aqueous phase from 30 minute crude oil upgrading experiment did not show any hydrocarbon compounds in the NMR spectra. The NMR results are discussed in Section 3 of the supplementary information.

Analytical Procedure

GC-FID

Gas products were analyzed using a Shimadzu GC-2010 with a $5 \mu \mathrm{L}$ sample-injection loop connected to an Rt-Q-Bond column (30 m, $530 \mu \mathrm{m}$ i.d., $20 \mu \mathrm{m}$ film thickness) and FID detector. 
The temperature program consisted of an initial temperature of $40^{\circ} \mathrm{C}$, which was maintained for 10 minutes, followed by a $5{ }^{\circ} \mathrm{C} / \mathrm{min}$ ramp to $150{ }^{\circ} \mathrm{C}$ with a 2-minute hold, and $12.5^{\circ} \mathrm{C} / \mathrm{min}$ ramp to $270^{\circ} \mathrm{C}$. Gas phase calibrations were performed using a calibration standard mixture from Airgas which contained aliphatic, aromatic, and sulfur compounds.

The mass fraction of carbon dioxide $\left(\mathrm{CO}_{2}\right)$ in the gas phase product was determined using an infrared analyzer (De Jaye). A $\mathrm{CO}_{2}$ calibration curve was made using standard mixtures in lecture bottles purchased from Sigma Aldrich.

\section{GC $\times$ GC-FID}

The organic phase liquid product from the experiments was analyzed using a GC×GC-FID (Agilent and Leco). The primary column was an RXi-5HT column with $30 \mathrm{~m}$ length, $250 \mu \mathrm{m}$ i.d. and $0.25 \mu \mathrm{m}$ film thickness. The secondary column was an RXi-17SIL MS column with $2 \mathrm{~m}$ length, $150 \mu \mathrm{m}$ i.d. and $0.15 \mu \mathrm{m}$ thickness. The modulation time was 16 seconds. The primary oven was held at a temperature of $50{ }^{\circ} \mathrm{C}$ for 0.5 minutes, followed by a $3{ }^{\circ} \mathrm{C} / \mathrm{min}$ ramp to $300^{\circ} \mathrm{C}$, and a final hold of 5 minutes. The secondary oven initial temperature was held at $75{ }^{\circ} \mathrm{C}$ for 0.5 minutes, followed by a $3{ }^{\circ} \mathrm{C} / \mathrm{min}$ ramp to $325^{\circ} \mathrm{C}$ and a hold time of 5 minutes. The species eluted from the column were analyzed using FID. FID response factors for alkanes, alkylaromatics, and polyaromatic hydrocarbons were obtained through analysis of standard solutions of model compounds, and the calibration factors of all the other intermediate compounds were determined by interpolating and extrapolating the calibration factors of model compounds. ${ }^{11}$ The procedure for determining the calibration factors and the species allocations in GC $\times$ GC-FID spectra is discussed in Section 4 and Section 5 of supplementary information. Peak volumes of individual peaks identified in the GC $\times$ GC-FID chromatograms were integrated using GC Image software from Zoex Corp. 
Lumped kinetic model

Product yields were fit using a kinetic model consisting of five lumps i.e., gas, gasoline, diesel, vacuum gas oil, and coke. The rate parameters of the model were estimated from experimental data using MATLAB R2016b. ${ }^{29}$ The input parameters to the MATLAB code were the product yield measured at different times, rate expressions, and initial guesses for the rate parameters. Optimal values of the rate constants were determined by minimizing the residual sum of squares criterion using the MATLAB functions Fmincon, Fsolve, Isqcurvefit. The optimization was constrained so that all rates were $\geq 0$, and the concentration of each lump was $\geq 0$, for all reaction times.

\section{RESULTS AND DISCUSSION}

Vacuum residue and SCW experiments

Vacuum residue was upgraded by treating it in SCW for reaction times ranging from 15 to 90 minutes, yielding gas, organic liquids (upgraded oil and reactor residue), and solids (coke), Figure 2. Greater than $85 \%$ of the mass of the feed was recovered gravimetrically post-reaction, and is shown by solid line in Figure 2. The mass fraction of gas and coke consistently increased with reaction time. At 90 minutes, 16 wt\% of the vacuum residue was converted to coke, consistent with the measurements of Zhao et al., ${ }^{18}$ who reported obtaining a coke yield of about15 wt $\%$ from upgrading vacuum residuum at similar experimental conditions to those investigated here $\left(440{ }^{\circ} \mathrm{C}\right.$, $25 \mathrm{MPa}, 90$ minutes). About $6.4 \mathrm{wt} \%$ of gas was formed at a reaction time of 60 minutes, which is similar to the $7.53 \mathrm{wt} \%$ of gas yield reported by Morimoto et al. ${ }^{16}$ in their study of oil sand bitumen upgrading at $450{ }^{\circ} \mathrm{C}, 30 \mathrm{MPa}$, and 60 minutes. The good agreement between gas and coke yields measured in this study compared to those in the literature is suggestive of good data 
reliability and encourages greater scrutiny of molecular level impacts of SCW treatment on the products.

Product distribution based on gas chromatography analysis

The total GC carbon recovery and GC×GC observed mass fraction are shown in Figure 3. The GC $\times$ GC observed mass fraction of the feed is only about $20 \%$, indicating that $80 \%$ of the feed consists of higher boiling point components $\left(>300^{\circ} \mathrm{C}\right)$ which were not vaporized at the GC inlet and therefore not detected. The GC×GC observed mass fraction of the liquids increased from 20 wt\% in the feed to $91 \mathrm{wt} \%$ after SCW treatment for 90 minutes. The increased mass fraction of GC analyzable components is attributable to cracking of heavy hydrocarbons present in the vacuum residue to form lighter hydrocarbons whose boiling points fall within the GC-detectable range. From a technological standpoint, the SCW-treatment increases the yield of fuel-range hydrocarbons, which is the primary desired outcome.

The GC $\times$ GC analyzable fraction is primarily a mixture of aliphatics and compounds with more than one aromatic ring. Both GC $\times$ GC observed mass fraction and the total GC carbon recovery increase with increasing reaction time (shown in Figure 2), due to an increase in the mass fraction of lower carbon number aliphatics and aromatic species present in the organic liquids and gas phase after SCW treatment. Figure 3 plots the GC observed mass fraction of aliphatics, alkylbenzenes, and multi-ringed hydrocarbons. Minor amounts of alkylbenzenes are also present in the feed and the SCW-treated feed. The mass fraction of fuel range hydrocarbons increases steadily with increasing reaction time up to $90 \mathrm{~min}$, from $2 \mathrm{wt} \%$ in the feed to $30 \mathrm{wt} \%$ after $90 \mathrm{~min}$ for aliphatics and from 11 to $34 \mathrm{wt} \%$ for hydrocarbons with $>1$ aromatic ring. In contrast, the alkylbenzene concentration increased from $6 \mathrm{wt} \%$ in the feed to $13 \mathrm{wt} \%$ after $90 \mathrm{~min}$ of reaction. Thus, the final product distribution indicates that the primary cracking products are aliphatics, 
followed by hydrocarbons with more than one aromatic ring, and then alkylbenzenes. The mass fractions of GC-detectable alkylbenzenes and liquid phase multi-ringed hydrocarbons did not change when the reaction time increased from 75 to $90 \mathrm{~min}$. The mass fractions of all the compounds and groups quantified in vacuum residue and organic liquids (15-90 minutes), are presented in Tables S3 - S8 in the supplementary information.

The primary components of the gas product were $\mathrm{C}_{1}-\mathrm{C}_{6}$ hydrocarbons. Apart from hydrocarbons, carbon dioxide $\left(\mathrm{CO}_{2}\right)$ was also measured in the gas products; Figure 4 summarizes the results, showing that the mass fraction of $\mathrm{CO}_{2}$ increased to about $0.01 \%$ after $30 \mathrm{~min}$ of reaction time. The $\mathrm{CO}_{2}$ yield was stable (within uncertainty) over the time range from 30 to $60 \mathrm{~min}$ at a value of approximately $0.008 \pm 0.002 \%$. The measured $\mathrm{CO}_{2}$ yields are in reasonable agreement with those reported by Morimoto et al. ${ }^{16}$ from their study of SCW upgrading of bitumen. Though Morimoto et al. ${ }^{16}$ reported a maximum $\mathrm{CO}_{2}$ yield of $0.8 \mathrm{wt} \%$, the difference is likely attributable mainly to differences in feed (bitumen compared to vacuum residue obtained from distillation of $\mathrm{AH})$ as the conditions of the two studies were comparable.

Three well-known mechanisms proposed in literature can explain $\mathrm{CO}_{2}$ formation. In the first mechanism, ${ }^{16} \mathrm{CO}_{2}$ forms directly by decomposition of oxygenated functional groups present in the crude oil. Decarboxylation or ketonization of naphthenic acids is the most likely route in the direct decomposition mechanisms. ${ }^{30-31}$ A second hypothesis is that a small amount of the hydrocarbons $^{32}$ are being reformed perhaps on some catalytic sites on the wall of the stainless steel reactor. However, stainless steel is not a good steam reforming catalyst and the reaction temperature is much lower that normally used for methane steam reforming. Any CO formed can undergo water-gas shift reaction to produce $\mathrm{CO}_{2}$. In the third mechanism, $\mathrm{CO}_{2}$ is produced from reaction of water with alkylsulfides present in crude oil. ${ }^{9}$ The reaction proceeds through cleavage 
of the C-S bond to form thioaldehyde, followed by pericyclic addition of water to form geminal mercaptoalcohol. The geminal mercaptoalcohol decomposes into aldehyde and $\mathrm{H}_{2} \mathrm{~S}$ via water catalyzed 6-membered ring transition state. The aldehyde decays to $\mathrm{CO}$ and pentane through radical reactions. Again, $\mathrm{CO}_{2}$ is formed as the terminal product via the water gas shift reaction.

Conclusively differentiating between the three mechanisms from the available data is not possible. However, quantitative considerations provide some insight. For the present experimental conditions, the maximum $\mathrm{CO}_{2}$ yield was $0.012 \mathrm{wt} \%$. This yield rules out extensive oxygenation of hydrocarbons contained in the feed during upgrading; however some minor oxygenation contribution cannot be ruled out entirely. The feed consists of 0.92 wt. \% of oxygen (Table S3 in supplementary information). Therefore, approximately $10 \%$ de-oxygenation of the feed can explain the observed $\mathrm{CO}_{2}$ yield. Since the feed may contain oxygen as ethers or other hydrothermally stable groups, $10 \%$ de-oxygenation is reasonable. In addition, the third mechanism i.e., hydrolysis of alkylsulfides may be a contributing pathway to produce $\mathrm{CO}_{2}$. A previous study ${ }^{12}$ reported that the combined thiophene and sulfide content of the GC $\times$ GC quantifiable portion of vacuum residue was approximately $0.08 \mathrm{wt} \%$, a figure is consistent with the $\mathrm{CO}_{2}$ yield measured in the current experiments. That stated, the agreement is likely fortuitous since the fraction of the feed that cannot be analyzed using GC likely contains sulfides and, in addition, no previous study has indicated formation of $\mathrm{CO}_{2}$ from decomposition of thiophene in SCW.

Whereas separate quantification of aliphatic components is difficult using single dimension GC due to co-elution of aliphatics and aromatics, GC $\times$ GC separates these two components, allowing them to be quantified separately. Figure 5 shows the mass fraction of the aliphatic content in the vacuum residue and the SCW upgraded oil. The vacuum residue fraction consists of $\mathrm{C}_{18}$ to $\mathrm{C}_{40}$ aliphatics comprised of alkanes and alkenes (predominantly straight, minor amounts of 
branched or cycloalkanes or cycloalkenes). In addition to the liquid-phase alkanes, gas phase products ranging from methane $\left(\mathrm{C}_{1}\right)$ to hexane $\left(\mathrm{C}_{6}\right)$ form during SCW-treatment of vacuum residue fraction and the overall mass fraction of $\mathrm{C}_{1}$ to $\mathrm{C}_{20}$ aliphatics increases from $0.5 \%$ to $30.7 \%$ after 90 min of treatment. In parallel, the total mass fraction of $\mathrm{C}_{21}$ to $\mathrm{C}_{40}$ aliphatics decreases from $2 \%$ to $0.16 \%$ over the same time span. The decrease in $\mathrm{C}_{21}$ to $\mathrm{C}_{40}$ aliphatics and the considerable increase in $\mathrm{C}_{1}-\mathrm{C}_{20}$ aliphatics suggests cracking of the long chain aliphatics with carbon numbers $\geq 21$. Because many of the aliphatic compounds originally present in the feed were insufficiently volatile to be analyzed via GC, the increased concentration of $\mathrm{C}_{1}-\mathrm{C}_{20}$ aliphatics is consistent with the increased fraction of the GC analyzable content observed in the treated oil product (Figure 2).

The thermal cracking mechanism of alkanes has been described previously in the literature. ${ }^{33-36}$ Alkanes undergo thermal cracking via C-C scission, $\beta$-scission and hydrogen abstraction reactions ${ }^{33}$ to produce shorter chain alkanes and alkenes. Consistent with the cracking of long chain alkanes, $\mathrm{C}_{2}-\mathrm{C}_{30}$ alkenes were observed in the organic liquids. As shown in Figure 6, the concentration of alkenes steadily increased from $0.09 \mathrm{wt} \%$ in the feed to $5 \mathrm{wt} \%$ after $90 \mathrm{~min}$ of reaction. For the reaction time of 90 min, the mass fraction of alkenes is 5-times less than the mass fraction of alkanes and iso-alkanes (5 vs. 25 wt. \%).

The observation that alkanes are 5-times more abundant in the organic liquids is curious since alkene/alkane ratio expected as the initial product of alkane cracking should be $1.0 .^{33}$ Similar to the current observation, Ford ${ }^{33}$ reported that the alkene/alkane ratio formed from thermal decomposition of hexadecane was less than 1.0 (for 300-370 ${ }^{\circ} \mathrm{C}$, $15-60 \mathrm{MPa}, 20.9 \%$ hexadecane conversion). To explain this observation, Ford ${ }^{33}$ suggested that the alkenes were consumed through addition reactions, where the alkene intermediates reacted with primary and secondary alkyl radicals to form branched and linear alkanes, both smaller and larger than n-hexadecane. In 
contrast, Liu et al. ${ }^{14}$ suggested that alkenes may be involved in the formation of coke precursors through addition reactions between aromatic radicals and olefins. In our experiments, an increase in concentration of multi-ringed hydrocarbon products was observed post-upgrading and alkenes may have participated in the growth of multi-ringed hydrocarbons. Moriya and Enomoto ${ }^{34}$ proposed another mechanism for reactivity of alkenes in SCW environments. Moriya and Enomoto $^{34}$ investigated polyethylene cracking in SCW and reported the formation of secondary alcohols and ketones in aqueous phase. The secondary alcohols and ketones were formed due to hydration of alkenes to alcohols, followed by oxidation to ketones. The aqueous phase from the current experiments was not analyzed using GC, therefore the mass fraction of alkenes consumed through this route is unknown. However, no long-chain $\left(>\mathrm{C}_{6}\right)$ alcohols were identified in the organic liquids (approximate detection limit for a single compound $0.002 \mathrm{wt} \%$ ). Cheng et al. ${ }^{17}$ also reported the absence of oxygen containing groups in the upgraded oil obtained from SCWtreatment of vacuum residue. Therefore for the current experimental conditions, alkene hydrolysis is considered a minor pathway.

Aside from alkanes, aromatics were the second most abundant product obtained from SCW-treatment of the vacuum residue. The GC analyzable portion of the vacuum residue feed consisted of alkylbenzenes with $\mathrm{C}_{11}-\mathrm{C}_{23}$ alkyl side chain carbons, alkylnaphthalenes with $\mathrm{C}_{5}-\mathrm{C}_{14}$ alkyl side chain carbons, and other aromatic hydrocarbons containing two to four aromatic rings. The product distributions of alkylbenzenes, alkylnaphthalenes, and multi-ringed hydrocarbons are plotted Figure 7 (a)-(d). From the figures, it can be observed that the concentration of shorter side chain alkylaromatics and multi-ringed hydrocarbons increases with increase in reaction time.

The cracking chemistry of alkylaromatics in thermal and SCW environments has been investigated in the literature. ${ }^{11,37-38}$. The side chains of alkylaromatics decay through C-C scission, 
$\mathrm{H}$-abstraction, reverse radical disproportionation and $\beta$-scission reactions to form shorter side chain alkylaromatics. For example, $\mathrm{C}_{1}-\mathrm{C}_{4}$ alkylaromatics form during SCW treatment of hexylbenzene ${ }^{11}$. Similarly in the current work, post-SCW treatment, the mass fraction of shorter chain, $\mathrm{C}_{1}-\mathrm{C}_{10}$ alkylbenzenes increased from $0.7 \%$ to $12.6 \%$ (shown in Figure 7 (a)). The mass fraction of $\mathrm{C}_{11}-\mathrm{C}_{23}$ alkylbenzenes initially decreased between 15-40 minutes but then remained constant for reaction times greater than 40 minutes. The net increase in the concentration of $\mathrm{C}_{1}$ $\mathrm{C}_{10}$ alkylbenzenes is greater than the net decrease in the concentration of $\mathrm{C}_{11}-\mathrm{C}_{23}$ alkylbenzenes. The significant increase in the concentration of $\mathrm{C}_{1}-\mathrm{C}_{10}$ alkylbenzenes suggests that the vacuum residue feed contains alkylbenzenes with alkyl side chains $>\mathrm{C}_{23}$, which were not quantified by GC. The alkylbenzenes $>\mathrm{C}_{23}$ presumably crack in the presence of SCW to produce both $\mathrm{C}_{1}-\mathrm{C}_{10}$ and $\mathrm{C}_{11}-\mathrm{C}_{23}$ alkylbenzenes. As a result, $\mathrm{C}_{11}-\mathrm{C}_{23}$ alkylbenzenes are both products and reactants, explaining their steady concentration over the time span of this study.

BTEX chemicals (benzene, toluene, ethylbenzene, xylenes) are an especially important class of aromatic products. On one hand, benzene content in gasoline is strictly regulated to limit human exposure. On the other, when purified, BTEX compounds are valuable solvents and precursor chemicals with greater value than conventional fuels. Figure 7 (b) shows the mass fractions of BTEX chemicals produced due to cracking of alkylbenzenes. Among the BTEX chemicals, the $C_{2}$ benzenes are most abundant followed by toluene. The yield of benzene is very small.

Figure 7(c) shows the time variation of the alkylnaphthalene mass fraction present in organic liquids. The yield of $\mathrm{C}_{0}$ to $\mathrm{C}_{4}$ alkylnaphthalenes increased steadily with increasing reaction time, whereas the yield of $\mathrm{C}_{5}-\mathrm{C}_{14}$ alkylnaphthalenes decreased. The main mechanism that can explain this inter-conversion is cracking of long-chain alkylnaphthalenes to produce short-chain 
versions, analogous to the chemistry observed previously here and elsewhere for alkylbenzenes. At short times, the observed increase in the yields of $\mathrm{C}_{0}$ to $\mathrm{C}_{4}$ alkylnapthalenes is insufficient to explain the observed loss of $\mathrm{C}_{5}-\mathrm{C}_{14}$ alkylnaphthalenes, suggesting that parallel reactions must be taking place. The most likely candidate is conversion of heavy alkylnaphthalenes to 3-4 ringed species, since the formation of 3-4 ring species (Figure 7(d)) is consistent with the decreased mass fraction of $\mathrm{C}_{5}-\mathrm{C}_{14}$ naphthalenes.

The concentrations of other 2-ring and 3-4 ringed species increased in the SCW-treated product fractions, as shown in Figure 7 (d). The concentrations of 2 and 3-ringed compounds increased for reaction times less than 40 minutes, and maintained stable values for reaction times greater than 40 minutes. In contrast, the yields of 4-ringed and higher multi-ring species consistently increased with increasing reaction time. The 2-4 ringed species can be formed through two pathways. In the first pathway, the alkylaroamatics undergo condensation reactions to form heavier aromatics. ${ }^{14}$ While the exact mechanism of formation of multi-ringed species is not known, a few studies in literature on thermal decomposition of alkylbenzenes also detected products that are heavier than the feed. Behar et $a l .{ }^{38}$ investigated thermal cracking of dodecylbenzene and observed formation of $\mathrm{C}_{1}, \mathrm{C}_{2}, \mathrm{C}_{7}-\mathrm{C}_{14}$ products as well as heavy $\mathrm{C}_{14+}$ aromatic fraction. In another study, Darouich et al. ${ }^{39}$ investigated the thermal cracking of the light aromatic fraction of Safaniya crude oil and observed the formation of 3-5 ringed compounds. Similarly, Liu et al. ${ }^{14}$ proposed the formation of 3-ring compounds from addition reactions between alkylnaphthalene radicals and olefins. Given the aforementioned discrepancy between formation and disappearance of alkylnaphthalenes, the most likely explanation for appearance of 3-4 ring compounds at short reaction times ( $<40$ minutes) involves conversion of alkylnaphthalenes to larger aromatic compounds. At higher reaction times ( $>40$ minutes), the heavier hydrocarbons in the vacuum 
residue, which were not quantifiable by GC, could crack to form 4-ring and higher multi-ring species, which are within the GC-quantifiable range.

Vacuum residue and SCW experiments product distribution classified into gas, gasoline, diesel, vacuum gas oil and coke lumps

GC $\times$ GC analysis contains detailed molecular information of the products composition that not only provides insight into specific pathways but can also be used to define product categories for kinetic analysis. Thus, the GC molecular data were classified into gas, gasoline, and diesel lumps to quantify the yield of useful fuels from vacuum residue upgrading (listed in Table S9 in supplementary information). Figure 8 shows the overall mass fraction of gas, gasoline, diesel, AR and coke in the vacuum residue feed and SCW-upgraded oil. The feed consists of $15 \mathrm{wt} \%$ diesel and $85 \mathrm{wt} \%$ AR. The mass fraction of AR decreases from $85 \mathrm{wt} \%$ in the feed to $6 \mathrm{wt} \%$, in the SCW-upgraded oil treated in SCW for $90 \mathrm{~min}$. The decreased AR content of SCW-treated vacuum residue corresponds with increased content of the gas, gasoline, coke, and diesel fractions. The maximum mass fraction of gasoline and diesel range components were $24 \%$ and $40 \%$ respectively, at 75 minutes of reaction time. At this same reaction time, the products contained $16 \mathrm{wt} \%$ coke.

A lumped kinetic model for upgrading of vacuum residue in SCW

The lumped kinetic models in literature ${ }^{19,22}$ for heavy oil upgrading in SCW investigated conversion of maltenes and asphaltenes to gas and coke. Similarly, Zhang et al. ${ }^{23}$ developed a fivelumped kinetic model for conversion between saturates, aromatics, resins, asphaltenes and coke. The unique contribution from this work is a five lump kinetic model for SCW upgrading of AR fraction of vacuum residue to gasoline, diesel, gas and coke fractions. Liu et al. ${ }^{19}$ modeled heavy oil pyrolysis in SCW as a two-phase system, i.e., SCW phase and oil phase. However, in this work, the vacuum residue and SCW experiments were modeled as a pseudo one-phase system to compare 
the rate parameters for formation of products in SCW upgrading vs. thermal cracking environment and due to lack of sufficient phase behavior and mass transfer data in the current work. The five lump kinetic model was developed using an approach similar to that recommended by Singh et al. ${ }^{40}$. Figure 9 is a schematic representation of the model, which includes pathways for AR to decompose to form gas, coke, and oil products. Unlike previous studies lacking detailed molecular composition data, the current data set could also be used to define a wide range of lumps, for example, lumps consisting of alkylbenzenes, 2-ring aromatics, etc. The current study focuses on gasoline and diesel due to their technological importance.

The lump model assumed first-order reaction kinetics for all reactions so that the rate equations of the reaction network become:

$\frac{d[A R]}{d t}=-\left(k_{1}+k_{2}+k_{3}+k_{4}\right)[A R]$

$\frac{d[D]}{d t}=k_{3}[A R]$

$\frac{d[G L N]}{d t}=k_{2}[A R]$

$\frac{d[G]}{d t}=k_{1}[A R]$

$\frac{d[C]}{d t}=k_{4}[A R]$

Initial conditions at $\mathrm{t}=0$, are: $[\mathrm{AR}]=\mathrm{AR}_{0},[\mathrm{D}]=\mathrm{D}_{0},[\mathrm{GLN}]=[\mathrm{G}]=[\mathrm{C}]=0$

All terms appearing in equations (5) - (9) are defined in Figure 9; square brackets in the equations refer to weight percentage of the various fractions at time t. Equations (5) - (9) are homogeneous differential equations and can be integrated over time with respect to their initial conditions. The resulting equations are shown in Section 10 in supplementary information. The rate constants, $\mathrm{k}_{1}-\mathrm{k}_{4}$ were determined by numerical optimization, as described in Section 2.4. 
Figure 10 shows that qualitative agreement between model predicted mass fractions and experimental observations is satisfactory; quantitatively, the agreement was always better than about $5 \%$. Figure 11 shows this comparison as a parity plot. The majority of predicted values are within the limits of the $95 \%$ prediction band; a handful of outliers fall on the very edge of this prediction band. The rate parameters themselves (Table 1), indicate that the major route of AR conversion is cracking to produce diesel and gasoline (with virtually identical rate constants), followed by formation of coke and gas.

No previous study on SCW upgrading of heavy oil provides a direct comparison of the reaction network parameters provided here. However, similar lumped kinetic models exist in literature for thermal cracking of vacuum residue to gas, gasoline, diesel and vacuum gas oil fractions. Therefore, the rate constants obtained in this study were compared with thermal cracking rate constants determined by Singh et al. ${ }^{40}$, to understand how the rate constants for vacuum residue upgrading in SCW compare against rate constants of similar lumped kinetic models in literature.

Singh et al. ${ }^{40}$ investigated the thermal cracking of 4 feedstocks, at temperatures ranging from 400 to $430{ }^{\circ} \mathrm{C}$ and for residence times between 3 and 15 minutes. Singh et al. ${ }^{40}$ developed a lumped kinetic model consisting of gas, gasoline, light gas oil (diesel), vacuum gas oil and feed lumps. To compare the parameters obtained from the thermal study with those reported here for SCW cracking, the feed and vacuum gas oil in the Singh et al. ${ }^{40}$ model were assumed to be equivalent to vacuum gas oil and coke, respectively. Among the four feedstocks investigated by Singh et al., Mathura refinery vis-breaker feed (MVBF) and Haldia refinery asphalt (HR asphalt) were the most similar to the AH vacuum residue studied here, with respect to asphaltene and sulfur weight percent. Therefore, the rate constants of the current model were compared with the rate 
constants determined for thermal cracking of MVBF and HR asphalt. Table 1 provides the results. The conversion of AR to gasoline was similar under thermal and SCW conditions. For all other reactions, the rate constants observed in this work were less than those reported by Singh et al. ${ }^{40}$ Most notably, the rate constant for the AR $\rightarrow$ Coke reaction obtained under SCW conditions was at least 8.4 times less than the rate constant observed under thermal conditions, consistent with water playing a role to inhibit coke formation. ${ }^{5,34}$

The lumped kinetic model shown in Figure 9 does not account for cracking of the diesel and gasoline lumps into lighter species; however the thermal stability of these products suggests that further cracking should be possible. ${ }^{11}$ Therefore, a modified version of the model was developed for converting diesel to gasoline $\left(\mathrm{k}_{5}\right)$ and gas $\left(\mathrm{k}_{6}\right)$, and for conversion of gasoline into gas $\left(\mathrm{k}_{7}\right)$. Optimization analysis indicated that the new rate constants $\left(\mathrm{k}_{5}-\mathrm{k}_{7}\right)$ did not improve the fit, probably because the rates of the secondary cracking reactions are much less than the rates of the primary reactions.

More than $85 \%$ of the feed was recovered post-reaction. The $10-15$ wt. \% loss of the feed could be attributed to loss of upgraded oil, which was stuck to the pipette tips, during transfer of oil from the centrifuge tube to glass vial (step b in Figure 1), and partly to the coke which was stuck to the bottom of the reactor and had to be collected using a spatula and also probable loss of reactor residue during clean-up of the reactor using dichloromethane (step c in Figure 1). Hence $10-15 \%$ loss of the feed can be attributed to three of the four major products, coke and organic liquids (upgraded oil and reactor residue). Therefore, the conversion of AR to gasoline, diesel and coke could be slightly higher if $100 \%$ of the mass was recovered. However, the predictions of the lumped kinetic model are consistent with the experiment, considering the experimental uncertainty 
of gravimetric quantification of the feed and products, so this measurement error is not expected to significantly affect the values of the fitting parameters.

Quantification of fuels and chemicals obtained by SCW treatment

GC $\times$ GC data were combined with product fractionation data to quantify the yields of fuels and chemicals obtained from distillation of AH followed by SCW treatment of heavy fraction. As mentioned previously, vacuum distillation of AH crude produced 37\% distillate and 63\% bottoms residue. Therefore, the mass fractions of the products from vacuum residue are scaled by $63 \%$. The distillate fraction was divided into gasoline, diesel and vacuum gas oil (AR) range components (Table S10-S13 in supplementary information). Figure 12(a) shows the mass fraction of gasoline, diesel, AR range components in the AH crude. About $58 \%$ of the $\mathrm{AH}$ crude oil consists of components in the AR range. The mass fraction of AR components in the oil recovered after 90 min of reaction time is $4 \%$. Figure 12(a) also shows that the AR mass fraction in SCW-treated vacuum residue is less than the AR mass fraction in the distillate, indicating the upgraded oil consists primarily of distillate range components. The remarkable decrease in AR fraction is associated primarily with formation of gasoline and diesel products, with minor production of gas and coke. The combined mass fraction of gasoline and diesel increased from $41.6 \%$ in the feed to 71.7\% after distillation followed by 90 min treatment of heavy fraction in SCW. Several highvalue chemicals such as alkenes, benzene, toluene, ethylbenzene and xylenes were also formed due to cracking of vacuum residue components (discussed in Section 3.1.1 and shown in Figure 12 (b)). When the mass fraction of alkenes and BTEX compounds in the distillate and SCW-treated residue are combined, it was about $9 \%$, which is about twice their content in the feed. The alkenes 
mass fraction in distillate, vacuum residue and SCW-treated vacuum residue is shown in Table S14 in supplementary information.

\section{CONCLUSIONS}

Arabian Heavy crude oil was vacuum-distilled at $350{ }^{\circ} \mathrm{C}$ to obtain distillate and vacuum residue fractions. The vacuum residue fraction was treated in SCW at $450{ }^{\circ} \mathrm{C}$ for $15-90$ minutes in a batch reactor. The product fractions were analyzed using gas chromatography (GC and GC×GCFID). The vacuum residue consisted of materials too heavy to be analyzed by GC plus some $\mathrm{C}_{21}{ }^{-}$ $\mathrm{C}_{40}$ aliphatics, alkylbenzenes, and alkylnaphthalenes with side chains containing $\mathrm{C}_{11}-\mathrm{C}_{23}$ and $\mathrm{C}_{5}$ $\mathrm{C}_{14}$ carbons respectively. The vacuum residue cracked in the presence of SCW to form $\mathrm{C}_{1}-\mathrm{C}_{20}$ aliphatics, $\mathrm{C}_{1}-\mathrm{C}_{10}$ alkylbenzenes and $\mathrm{C}_{0}-\mathrm{C}_{4}$ alkylnaphthalenes. The $\mathrm{GC} \times \mathrm{GC}$ observed mass fraction was more than $90 \%$ at a reaction time of 90 minutes, a substantial increase compared to the initial value (20\%). The GC-analyzable portion of vacuum residue also contained small amounts of 3-4 ring compounds, and the concentration of these 3-4 ring compounds increased post-SCW treatment. SCW-treatment of vacuum residue resulted in formation of gas $\left(\mathrm{C}_{1}-\mathrm{C}_{6}\right.$ species) and coke products as well. Direct participation of water as a reactant was likely minimal, as less than $0.01 \% \mathrm{CO}_{2}$ was detected in the product gas, a yield which could be attributed to deoxygenation of the feed and/or reaction of water with sulfides.

The GC $\times$ GC analysis provided detailed information on the SCW upgrading chemistry and the yields of chemicals and transportation fuels. High value chemicals such as $\mathrm{C}_{6}-\mathrm{C}_{30}$ alkenes and BTEX compounds were formed from vacuum residue due to cracking of the alkyl chains. In total, BTEX compounds and olefins constituted 9\% of the products, which may be significant given their value as chemicals. Likewise, the mass fraction of usable fuels such as diesel and gasoline almost doubled after SCW treatment. 
The molecular level data from gas chromatography was used to classify the feed and products into gas, gasoline, diesel, vacuum gas oil, and coke lumps. A first order 5-lump kinetic model was developed to describe the cracking of vacuum gas oil range components into other four lumps The rate parameters were estimated from the experimental data to show that cracking of vacuum gas oil to produce diesel and gasoline products were the major pathways. Interestingly, conversion of gas oil to coke was reduced by a factor of 8.4 compared to that reported in the literature from study of thermal cracking in the absence of water. In contrast, cracking of vacuum gas oil to produce gasoline was not affected by the presence of SCW. These results provide a quantitative basis for optimizing the use of SCW to convert heavy oils into useful fuels and chemicals and demonstrate the value of GC $\times$ GC for understanding the processes occurring in complex feeds.

\section{ACKNOWLEDGEMENTS}

The authors gratefully acknowledge the support of Saudi Aramco for funding this study under Contract Number 6600023444.We thank Perman Jorayev (Korea Advanced Institute of Science and Technology) for helping to improve the gas chromatography method to separate alkenes from the product mixture. Prof. Kristala Prather (MIT) generously permitted use of her group’s rotary evaporator.

\section{SUPPLEMENTARY INFORMATION}

The supplementary information consists of sections on GC $\times$ GC calibrations, pressure profile of the batch reactor, a representative GC $\times$ GC spectra of upgraded oil, GC $\times$ GC analysis of reactor residue and upgraded oil, proton NMR analysis of aqueous phase sample post-reaction, elemental analysis of vacuum residue, hydrocarbon composition of reactor residue and upgraded oil for varied reaction times, hydrocarbon composition in distillate fraction, mass fraction of alkenes in 
distillate, vacuum residue and upgraded oil, information about gas, gasoline, diesel, coke and AR lumps in distillate, vacuum residue and upgraded oil, and the analytical solution of the model equations.

\section{LITERATURE CITED}

1. Huc AY. Heavy crude oils : from geology to upgrading: an overview. Paris: Editions Technip., 2011.

2. Forsberg CW. Future hydrogen markets for large-scale hydrogen production systems. International Journal of Hydrogen Energy. 2007; 32: 431-439.

3. Caniaz RO, Erkey C. Process intensification for heavy oil upgrading using supercritical water. Chemical Engineering Research and Design. 2014; 92: 1845-1863.

4. Choi KH. Supercritical water process to upgrade petroleum. US Patent 8,864,978, October $21,2014$.

5. Li N, Yan B, Xiao X. A review of lab-scale research on upgrading heavy oil in supercritical water. Energies. 2015; 8: 8962-8989.

6. Furimsky E. Emissions of carbon dioxide from tar sands plants in Canada. Energy \& Fuels. 2003; 17: 1541-1548.

7. Elgowainy A, Han J, Cai H, Wang M, Forman GS, DiVita VB. Energy efficiency and greenhouse gas emission intensity of petroleum products at U.S. refineries. Environmental Science and Technology. 2014; 48: 7612-7624.

8. Patwardhan PR, Timko MT, Class CA, Bonomi RE, Kida Y, Hernandez HH, Tester JW, Green WH. Supercritical water desulfurization of organic sulfides is consistent with freeradical kinetics. Energy \& Fuels. 2013; 27: 6108-6117. 
9. Kida Y, Class CA, Concepcion AJ, Timko MT, Green WH. Combining experiment and theory to elucidate the role of supercritical water in sulfide decomposition. Physical Chemistry Chemical Physics. 2014; 16: 9220-9228.

10. Kida, Y. Supercritical water desulfurization of crude oil. $\mathrm{PhD}$ dissertation, Massachusetts Institute of Technology, 2014.

11. Carr AG, Class CA, Lai L, Kida Y, Monrose T, Green WH. Supercritical water treatment of crude oil and hexylbenzene: An experimental and mechanistic study on alkylbenzene decomposition. Energy \& Fuels. 2015; 29: 5290-5302.

12. Kida Y, Carr AG, Green WH. Cleavage of side chains on thiophenic compounds by supercritical water treatment of crude oil quantified by two-dimensional gas chromatography with sulfur chemiluminescence detection. Energy \& Fuels. 2014; 28: 6589-6595.

13. Timko MT, Ghoniem AF, Green WH. Upgrading and desulfurization of heavy oils by supercritical water. The Journal of Supercritical Fluids. 2015; 96: 114-123.

14. Liu Y, Bai F, Zhu C, Yuan P. Upgrading of residual oil in sub- and supercritical water: An experimental study. Fuel Processing Technology. 2013; 106: 281-288.

15. Watanabe M, Kato S, Ishizeki S, Inomata H, Smith RJ. Heavy oil upgrading in the presence of high density water: Basic study. The Journal of Supercritical Fluids. 2010; 53: 48-52.

16. Morimoto M, Sugimoto Y, Saotome Y, Sato S, Takanohashi T. Effect of supercritical water on upgrading reaction of oil sand bitumen. The Journal of Supercritical Fluids. 2010; 55: 223-231. 
17. Cheng Z, Ding Y, Zhao L, Yuan P, Yuan W. Effects of supercritical water in vacuum residue upgrading. Energy \& Fuels. 2009; 23: 3178-3183.

18. Zhao L, Cheng Z, Ding Y, Yuan P, Lu S, Yuan W. Experimental study on vacuum residuum upgrading through pyrolysis in supercritical water. Energy \& Fuels. 2006; 20: 2067-2071.

19. Liu Q, Zhu D, Tan X, Yuan P, Cheng Z, Yuan W. Lumped reaction kinetic models for pyrolysis of heavy oil in the presence of supercritical water. AIChE Journal. 2016; 62: 207216.

20. Arcelus-Arrillaga P, Pinilla JL, Hellgardt K, Millan M. Applications of water in hydrothermal conditions for upgrading heavy oils: A review. Energy Fuels. 2017; 31: 4571-4587.

21. Yan T, Xu J, Litao W, Liu Y, Yang C, Fang T. A review of upgrading heavy oils with supercritical fluids. Royal Society of Chemistry Advances. 2015; 5: 75129-75140.

22. Tan X, Liu Q, Zhu D, Yuan P, Cheng Z, Yuan W. Pyrolysis of heavy oil in the presence of supercritical water: The reaction kinetics in different phases. AIChE Journal. 2015; 61: 857-866.

23. Zhang D, Ren Z, Wang D, Lu K. Upgrading of crude oil in supercritical water: A fivelumped kinetic model. Journal of Analytical and Applied Pyrolysis. 2017; 123: 56-64.

24. Ancheyta J. Modeling and simulation of catalytic reactors for petroleum refining. John Wiley \& Sons, Inc., 2011.

25. Rana MS, Samano V, Ancheyta J, Diaz JAI. A review of recent advances on process technologies for upgrading of heavy oils and residua. Fuel. 2007; 86: 1216-1231. 
26. Stratiev D, Dinkov R, Petkov K, Stanulov K. Evaluation of crude oil quality. Petroleum \& Coal. 2010; 52: 35-43.

27. Gibbs L, Anderson B, Barnes K, Engeler G, Freel J, Horn J, Ingham M, Kohler D, Lesnini D, MacArthur R, Mortier M, Peyla D, Taniguchi B, Tiedemann A, Welstand S, Bernhardt D, Collini K, Farr A, Jones J, Lind J, Tom C. Motor Gasolines Technical Review (FTR-1). Chevron Corporation, 2009.

28. Bacha J, Freel J, Gibbs A, Gibbs L, Hemighaus G, Hoekman K, Horn J, Gibbs A, Ingham M, Jossens L, Kohler D, Lesnini D, McGeehan J, Nikanjam M, Olsen E, Organ R, Scott B, Sztenderowicz M, Tiedemann A, Walker C, Lind J, Jones J, Scott D, Mills J. Diesel Fuels Technical Review. Chevron Corporation, 2007.

29. MATLAB R2016b, The Mathworks, 2016.

30. Renz M. Ketonization of carboxylic acids by decarboxylation: Mechanism and scope. European Journal of Organic Chemistry. 2005; 6: 979-988.

31. Ding L, Rahimi P, Hawkins R, Bhatt S, Shi Y. Naphthenic acid removal from heavy oils on alkaline earth-metal oxides and ZnO catalysts. Applied Catalysis A: General. 2009; 371: $121-130$.

32. Hosseinpour M, Ahmadi SJ, Fatemi S. Deuterium tracing study of unsaturated aliphatics hydrogenation by supercritical water in upgrading heavy oil. Part 1: Non-catalytic cracking. The Journal of Supercritical Fluids. 2016. 107: 278-285.

33. Ford T. Liquid-Phase Thermal Decomposition of Hexadecane: Reaction Mechanisms. Industrial \& Engineering Chemistry Research. 1986; 25: 240-243.

34. Moriya T, Enomoto H. Characteristics of polyethylene cracking in supercritical water compared to thermal cracking. Polymer Degradation and Stability. 1999; 65: 373-386. 
35. Khorasheh F, Gray MR. High-pressure thermal cracking of n-hexadecane. Industrial Engineering Chemistry Research. 1993; 32: 1853-1863.

36. Jackson KJ, Burnham AK, Braun RL, Knauss KG. Temperature and pressure dependence of n-hexadecane cracking. Organic Geochemistry. 1995; 23: 941-953.

37. Scacchi G, Marquaire P, Burkle-Vitzthum V, Michels R. Mechanistic modeling of the thermal cracking of decylbenzene, application to the prediction of its thermal stability at geological temperatures. Industrial Engineering Chemistry Research. 2003; 42: 57915808.

38. Behar F, Lorant F, Budzinski H, Desavis E. Thermal stability of alkylaromatics in natural systems: kinetics of thermal decomposition of dodecylbenzene. Energy \& Fuels. 2002; 16: 831-841.

39. Darouich TA, Behar F, Largeau C. Thermal cracking of the light aromatic fraction of safaniya crude oil-experimental study and compositional modelling of molecular classes. Organic Geochemistry. 2006; 37: 1130-1154.

40. Singh J, Kumar MM, Saxena AK, Kumar S. Reaction pathways and product yields in mild thermal cracking of vacuum residues: A multi-lump kinetic model. Chemical Engineering Journal. 2005; 108: 239-248 


\section{LIST OF FIGURE CAPTIONS}

Figure 1. Experimental procedure for vacuum residue and SCW experiments (a) Distillation of Arabian Heavy crude oil to produce distillate and vacuum residue fractions (b) SCW treatment of vacuum residue fraction in a batch reactor setup and analysis of gas phase products using GC-FID and organic product (upgraded oil) using GCXGC (c) The oil (reactor residue) and coke sample left in the reactor was collected using dichloromethane (DCM) as a solvent. The oil and coke sample was filtered to collect coke and DCM was evaporated to collect reactor residue. Nomenclature: GC $\times$ GC- Two-dimensional gas chromatography, FID - Flame Ionization Detector.

Figure 2. Mass fraction of products from vacuum residue and SCW experiments.

Figure 3. Mass fraction of hydrocarbons (HC), total GC carbon recovery and GC $\times$ GC observed mass fraction in feed (0 min) and SCW treated product (15-90 min).

Figure 4. Mass fraction of $\mathrm{CO}_{2}$ measured in vacuum residue and SCW upgrading experiments.

Figure 5. Mass fraction of $\mathrm{C}_{1}-\mathrm{C}_{40}$ aliphatics in vacuum residue and SCW experiments. $\mathrm{C}_{1}-\mathrm{C}_{6}$ aliphatics measured using gas phase GC-FID, $\mathrm{C}_{6}-\mathrm{C}_{40}$ aliphatics measured using GC×GC-FID.

Figure 6. Mass fraction of $\mathrm{C}_{2}$ - $\mathrm{C}_{30}$ alkenes in vacuum residue and SCW experiments. $\mathrm{C}_{2}-\mathrm{C}_{6}$ alkenes measured using gas phase GC-FID, $\mathrm{C}_{6}-\mathrm{C}_{30}$ alkenes measured using GC×GC-FID.

Figure 7. Mass fractions of (a) alkylbenzenes, (b) BTEX compounds (c) alkylnapthalenes and (d) multi-ringed species other than naphthalenes in vacuum residue and SCW experiments. $\mathrm{C}_{1}$ benzene is toluene, $\mathrm{C}_{2}$ benzene is an akylbenzene with side chains consisting of 2 carbons (for example ethylbenzene, styrene or xylenes). 
Figure 8. Vacuum residue and SCW experimental data presented as gas, gasoline, diesel, vacuum gas oil and coke lumps.

Figure 9. Lump model proposed to describe SCW upgrading of AR.

Figure 10. Experiments and modeling prediction of mass fraction of lumps in vacuum residue upgrading in SCW.

Figure 11. Parity plot of the predicted values of lumped kinetic model versus experimental data.

Figure 12. (a) Usable fuels in Arabian Heavy crude oil and SCW-treated vacuum residue (b) fuels and high-value chemicals in distillate and SCW-treated vacuum residue. Numbers denote mass fraction. AR - Vacuum gas oil. 

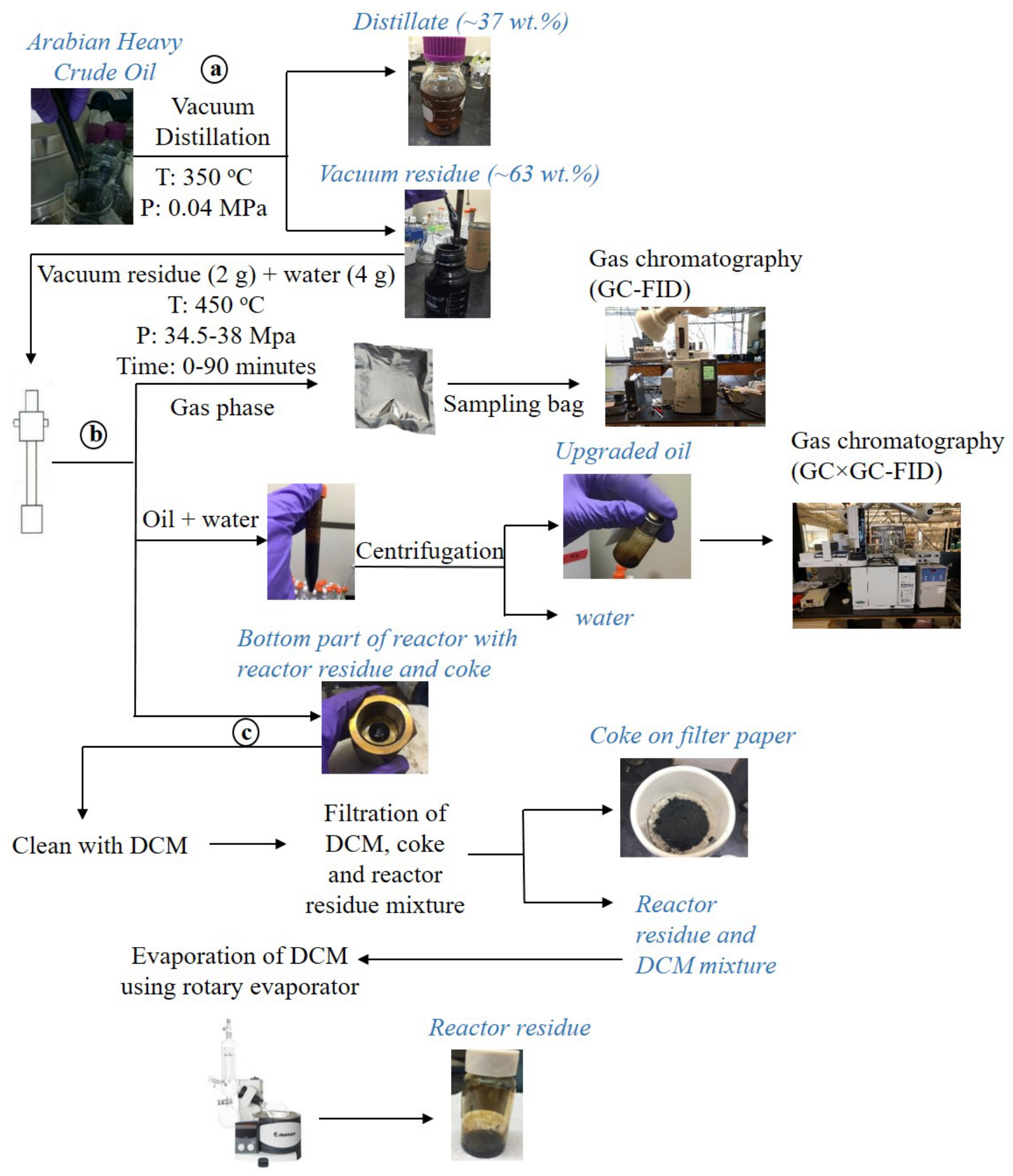

Figure 13. Experimental procedure for vacuum residue and SCW experiments (a) Distillation of Arabian Heavy crude oil to produce distillate and vacuum residue fractions (b) SCW treatment of vacuum residue fraction in a batch reactor setup and analysis of gas phase products using GC-FID and organic product (upgraded oil) using GC $\times$ GC (c) The oil 
(reactor residue) and coke sample left in the reactor was collected using dichloromethane (DCM) as a solvent. The oil and coke sample was filtered to collect coke and DCM was evaporated to collect reactor residue. Nomenclature: GC $\times$ GC- Two-dimensional gas chromatography, FID - Flame Ionization Detector. 


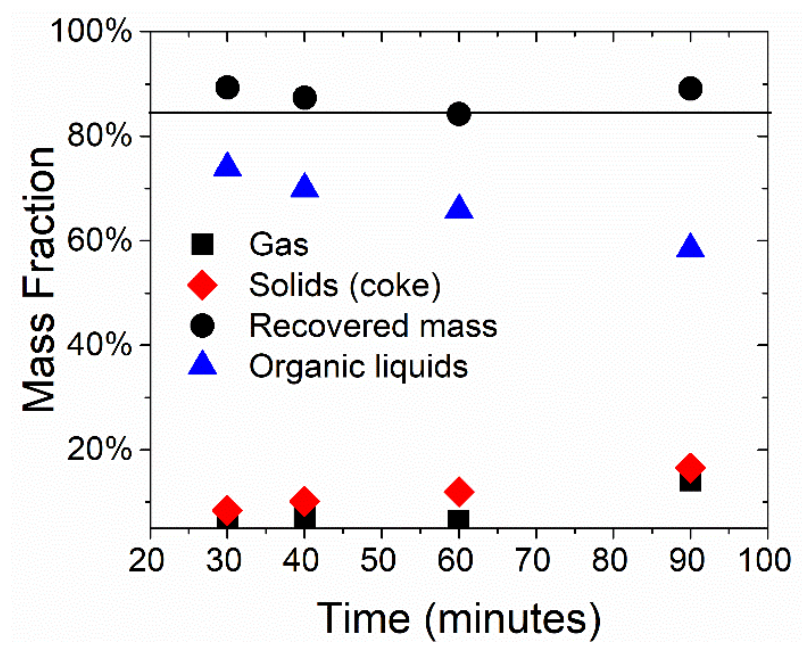

Figure 14. Mass fraction of products from vacuum residue and SCW experiments. 


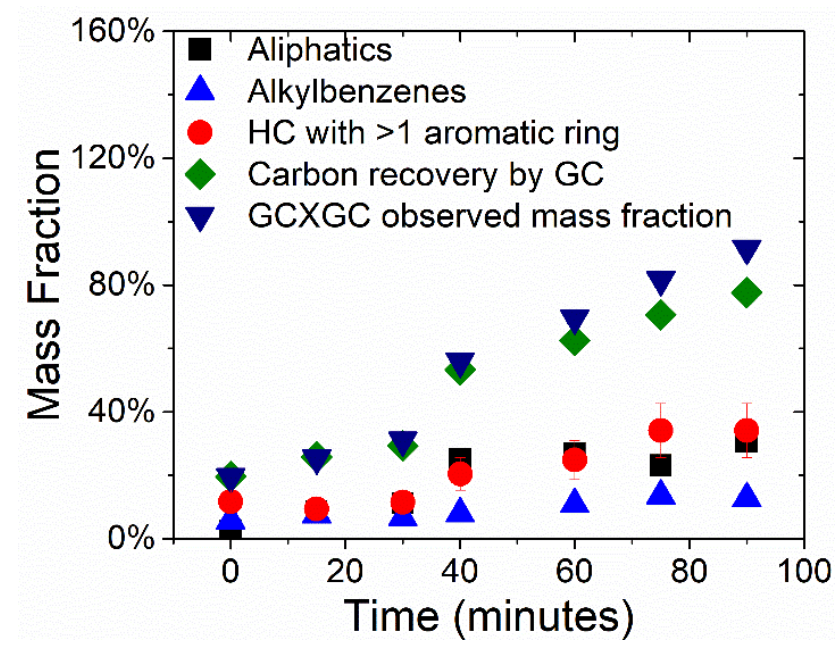

Figure 15. Mass fraction of hydrocarbons (HC), total GC carbon recovery and GC $\times$ GC observed mass fraction in feed (0 min) and SCW treated product (15-90 min). 


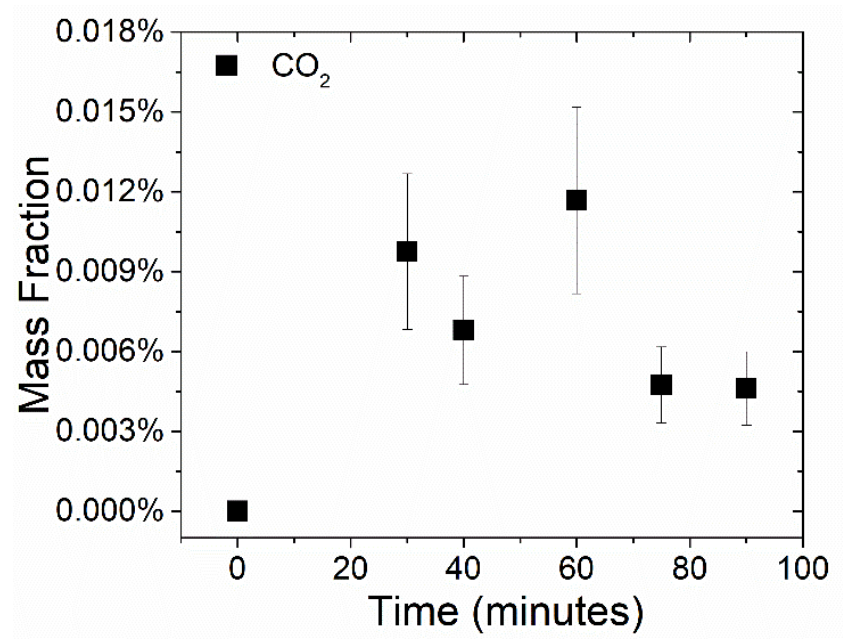

Figure 16. Mass fraction of $\mathrm{CO}_{2}$ measured in vacuum residue and SCW upgrading experiments. 


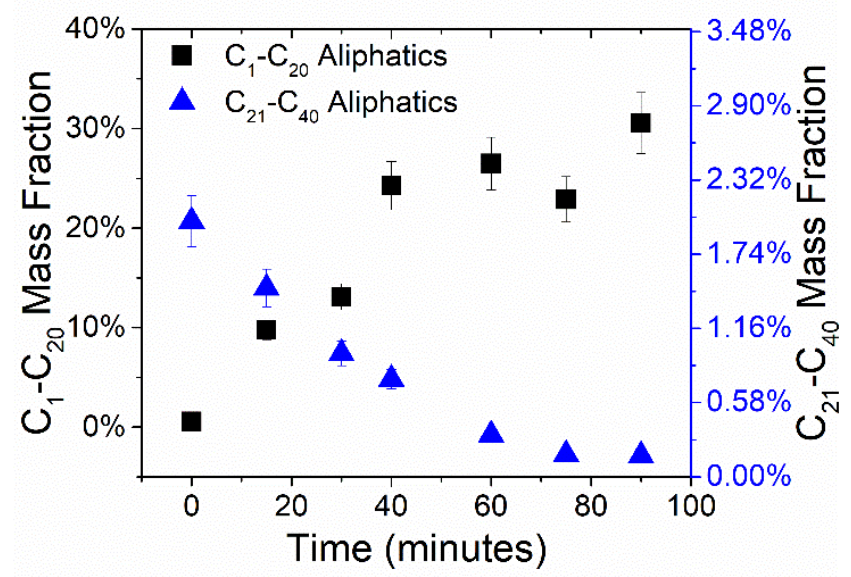

Figure 17. Mass fraction of $\mathrm{C}_{1}-\mathrm{C}_{40}$ aliphatics in vacuum residue and $\mathrm{SCW}$ experiments. $\mathrm{C}_{1}$ $\mathrm{C}_{6}$ aliphatics measured using gas phase $\mathrm{GC}-\mathrm{FID}, \mathrm{C}_{6}-\mathrm{C}_{40}$ aliphatics measured using GC $\times$ GCFID. 


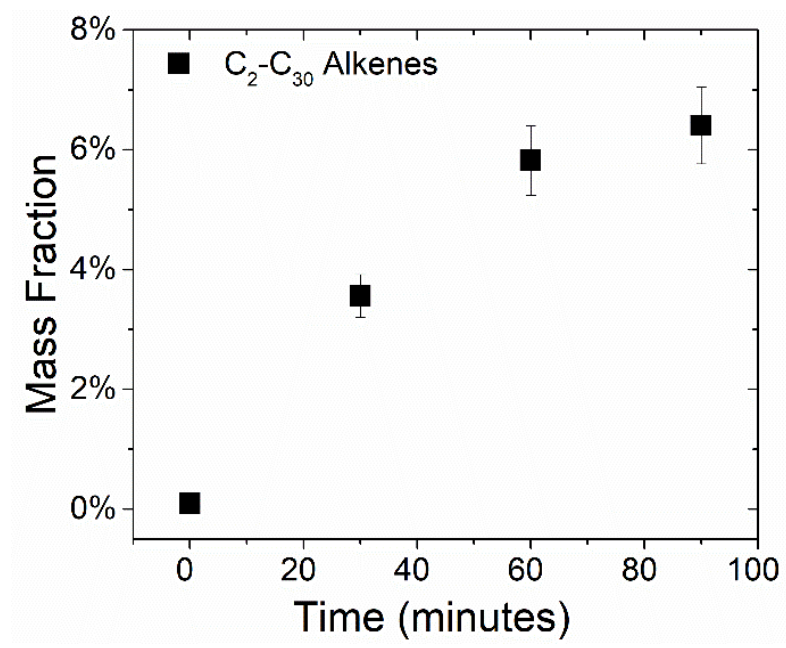

Figure 18. Mass fraction of $\mathrm{C}_{2}-\mathrm{C}_{30}$ alkenes in vacuum residue and $S C W$ experiments. $C_{2}-C_{6}$ alkenes measured using gas phase GC-FID, $\mathrm{C}_{6}-\mathrm{C}_{30}$ alkenes measured using GC $\times$ GC-FID. 

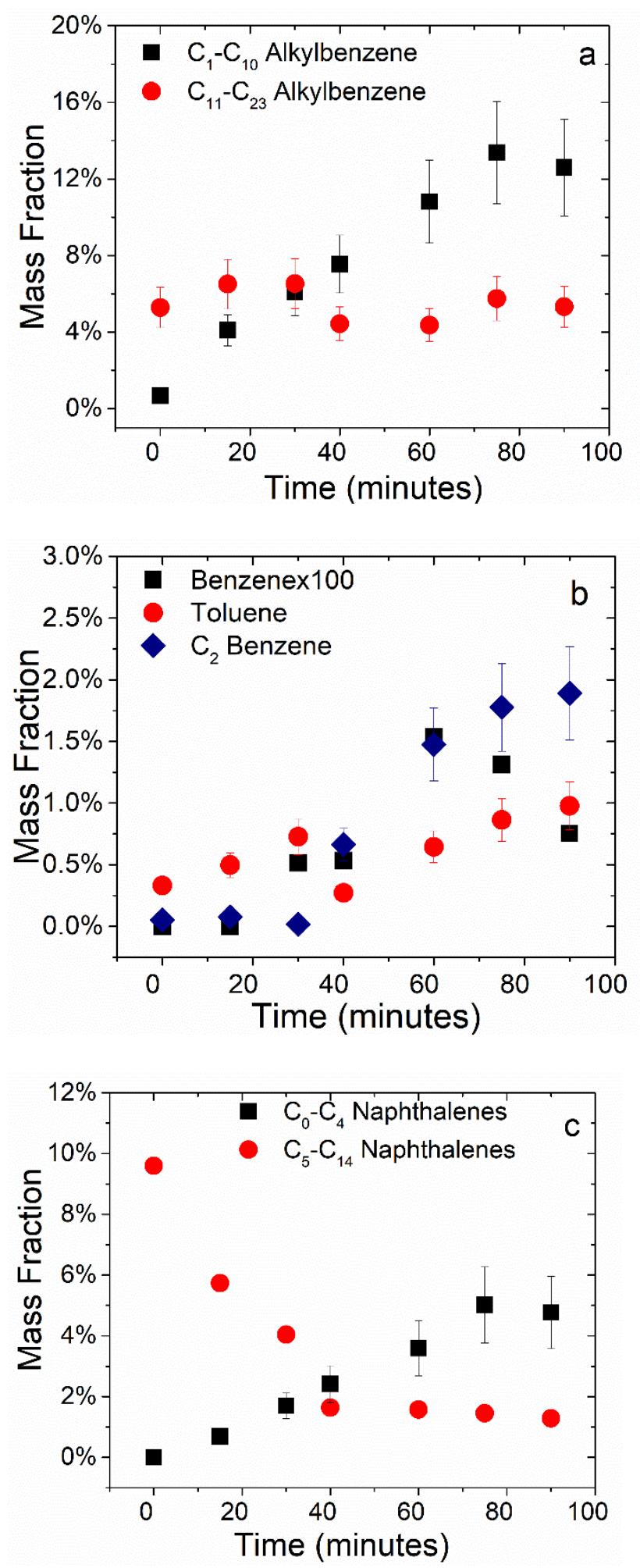


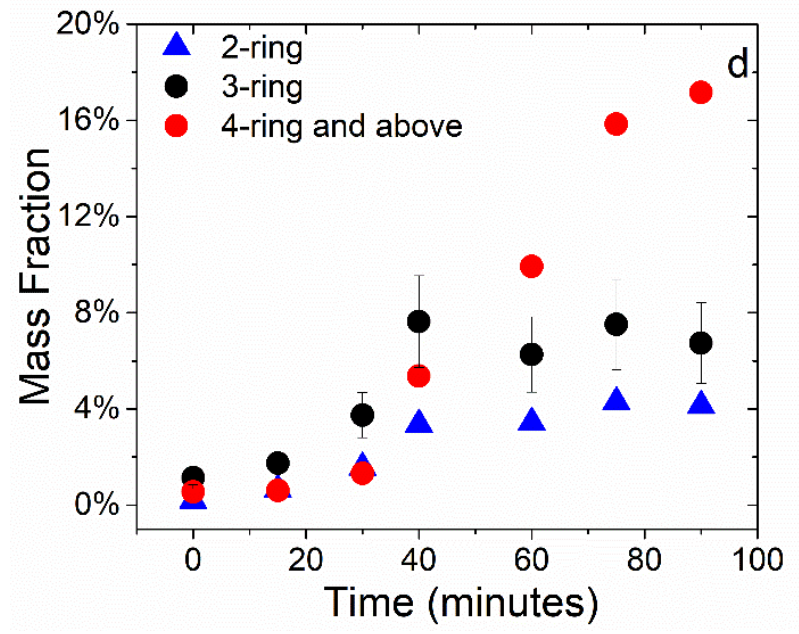

Figure 19. Mass fractions of (a) alkylbenzenes, (b) BTEX compounds (c) alkylnapthalenes and (d) multi-ringed species other than naphthalenes in vacuum residue and SCW experiments. $C_{1}$ benzene is toluene, $C_{2}$ benzene is an akylbenzene with side chains consisting of 2 carbons (for example ethylbenzene, styrene or xylenes). 


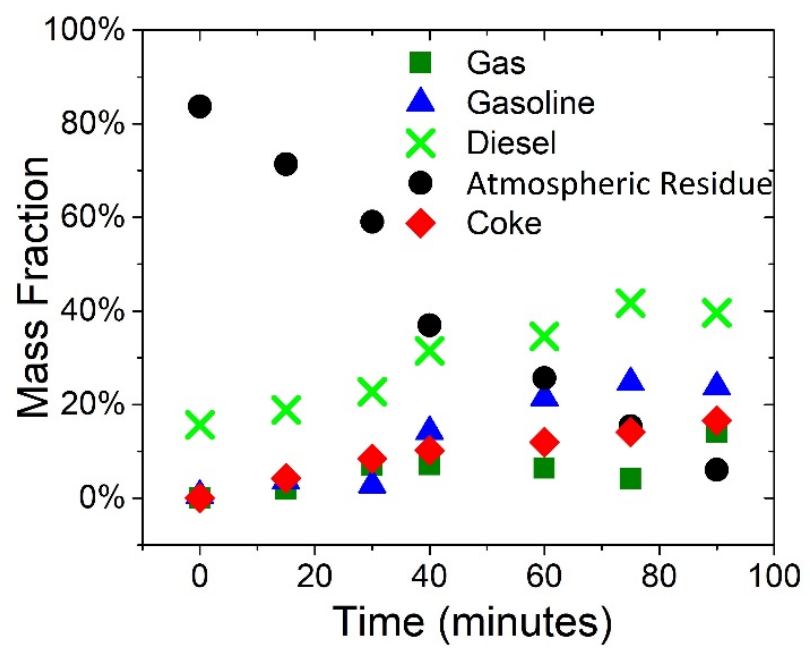

Figure 20. Vacuum residue and SCW experimental data presented as gas, gasoline, diesel, vacuum gas oil and coke lumps. 


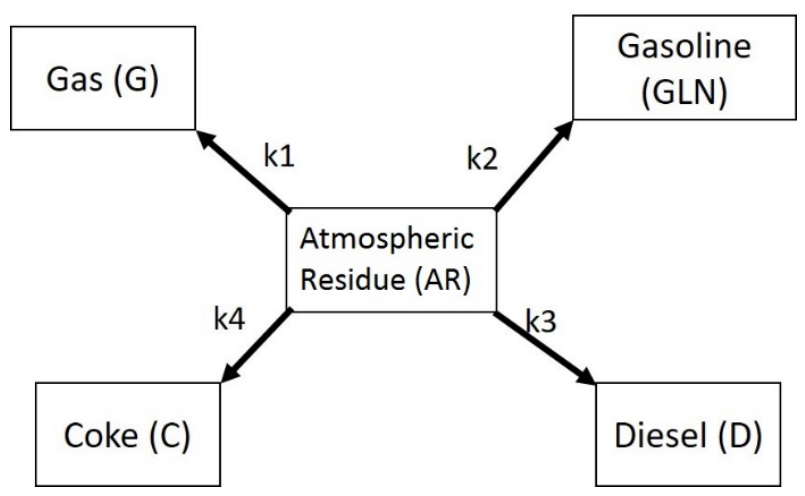

Figure 21. Lump model proposed to describe SCW upgrading of AR. 


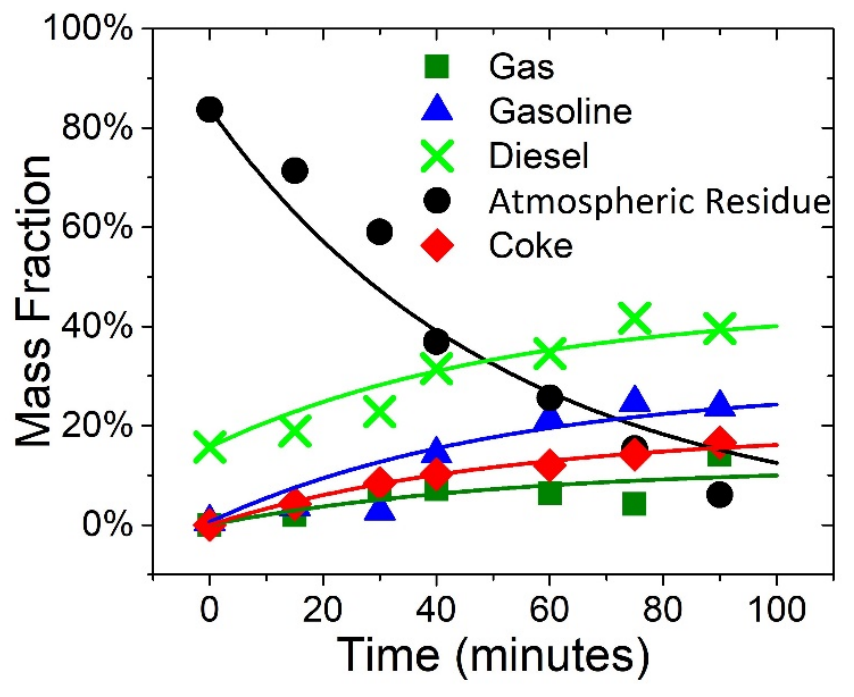

Figure 22. Experiments and modeling prediction of mass fraction of lumps in vacuum residue upgrading in SCW. 


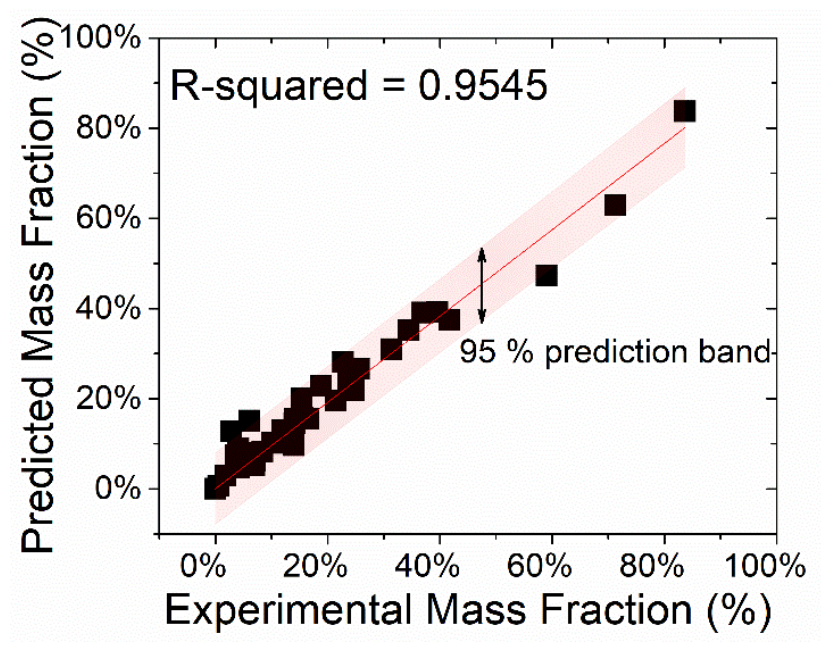

Figure 23. Parity plot of the predicted values of lumped kinetic model versus experimental data. 

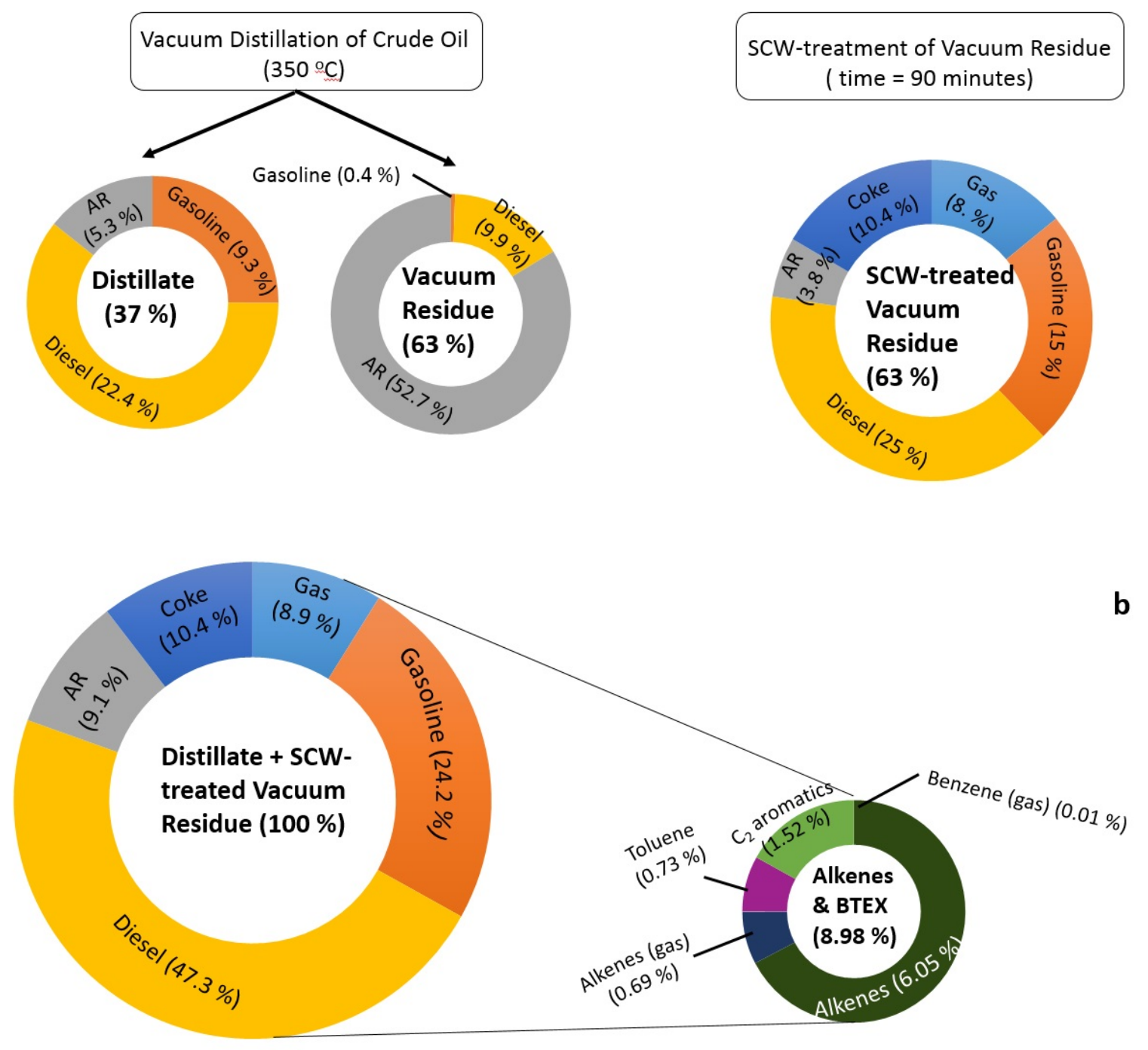

Figure 24. (a) Usable fuels in Arabian Heavy crude oil and SCW-treated vacuum residue (b) fuels and high-value chemicals in distillate and SCW-treated vacuum residue. Numbers denote mass fraction. AR - Vacuum gas oil. 
Table 1. Kinetic parameters for vacuum residue upgrading in SCW $($ Temperature $=450$ $\left.{ }^{\circ} \mathbf{C}\right)$.

\begin{tabular}{|c|c|c|c|}
\hline Reaction & Rate constan & $\left(\min ^{-1}\right)$ & \\
\hline & $\begin{array}{l}\text { Thermal cracking } \\
\text { Singh et al. }{ }^{40}\end{array}$ & $\begin{array}{l}\text { SCW cracking } \\
\text { this work }\end{array}$ & $\begin{array}{l}\text { Ratio of Singh et al. }{ }^{40} \text { and } \\
\text { current study rate } \\
\text { constants }\end{array}$ \\
\hline $\mathrm{AR} \rightarrow \mathrm{Gas}\left(\mathrm{k}_{1}\right)$ & $0.0069-0.0187$ & 0.0027 & $2.6-6.9$ \\
\hline AR $\rightarrow$ Gasoline $\left(\mathrm{k}_{2}\right)$ & $0.0021-0.0259$ & 0.0063 & $0.3-4.1$ \\
\hline AR $\rightarrow$ Diesel $\left(k_{3}\right)$ & $0.0173-0.0616$ & 0.0065 & $2.7-9.5$ \\
\hline AR $\rightarrow$ Coke $\left(k_{4}\right)$ & $0.0362-0.0711$ & 0.0043 & $8.4-16.5$ \\
\hline
\end{tabular}




\section{TABLE OF CONTENTS}

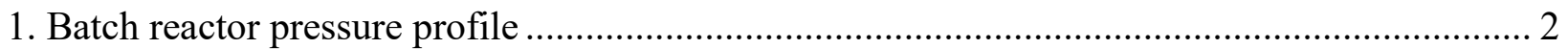

2. GC $\times$ GC Analysis of Reactor Residue and Upgraded Oil .................................................... 3

3. Proton NMR analysis of aqueous phase of crude upgrading experiments (reaction time $=30$

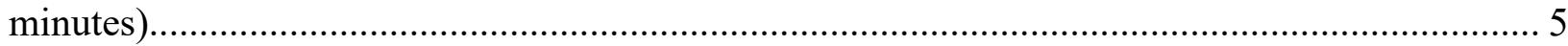

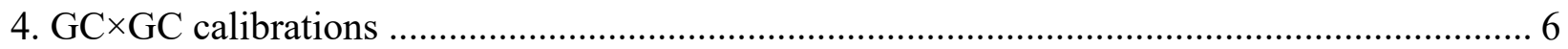

5. $\mathrm{GC} \times \mathrm{GC}$ spectra of upgraded oil and species information ............................................. 8

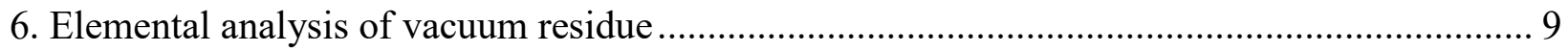

7. $\mathrm{GC} \times \mathrm{GC}$ analysis of vacuum residue and upgraded oil at varied reaction times .................... 10

8. GC $\times \mathrm{GC}$ Analysis of Distillate fraction...................................................................... 15

9. Alkenes mass fraction in distillate, vacuum residue and SCW-treated vacuum residue ......... 18

10. Equations for decay of AR and formation of gas, gasoline, diesel and coke products.......... 19

\section{LIST OF FIGURES}

Figure S 1. The pressure profile in the batch reactor for a representative 30 minute run............. 3 Figure S 2. GC $\times$ GC spectra of (a) vacuum residue (b) upgraded oil and (c) reactor residue in vacuum residue and SCW experiment (time $=30$ minutes). Carbon disulfide was used as diluent and 3-chlorothiophene was used as an external standard.

Figure S 3. Mass fraction of aliphatics, alkylbenzenes, multi-ring species and unquantified fraction in upgraded oil and reactor residue from vacuum residue and SCW experiments (time $=30$ minutes).

Figure S 4. GC $\times$ GC-FID calibration factor of alkanes determined as a function of carbon number.

Figure $\mathrm{S} 5 . \mathrm{GC} \times \mathrm{GC}$ spectra of upgraded oil (75 minute run), showing the allocation of major hydrocarbon classes and species.

\section{LIST OF TABLES}

Table S 1. Exponential regression equations for the determination of calibration factors (mole fraction/signal) based on the number of carbons, for alkanes, alkenes, alkylbenzenes and alkylnaphthalenes. 7

Table S 2. Elemental analysis of vacuum residue...... 9 Table S 3. Raw results of g compound/ $g$ total weight vacuum residue as obtained by the GC-FID (gas phase) and $\mathrm{GC} \times \mathrm{GC}-\mathrm{FID}$ analysis (liquid phase).Blue font: gas phase species, orange: gasoline range species, yellow: diesel range species, grey: AR range species. 10 
Table S4. Raw results of $\mathrm{g}$ compound/ $\mathrm{g}$ total weight vacuum residue as obtained by GC $\times$ GC-FID analysis (continued). Orange font: gasoline range species, yellow: diesel range species, grey: AR range species

Table S 6. Raw results of g compound/ g total weight vacuum residue as obtained by GC $\times$ GC-FID analysis (continued). Orange font: gasoline range species, yellow: diesel range species, grey: AR range species 12

Table S 7. Raw results of g compound/ $\mathrm{g}$ total weight vacuum residue as obtained by $\mathrm{GC} \times \mathrm{GC}$-FID analysis (continued). Orange font: gasoline range species, yellow: diesel range species, grey: AR range species. 13 Table S 8. Raw results of $g$ compound/ $g$ total weight vacuum residue as obtained by GC $\times$ GC-FID analysis (continued) 14 Table S 9. Mass fraction of vacuum gas oil, diesel, gasoline, gas and coke lumps in vacuum residue $+\mathrm{SCW}$ experiments 14

Table S 10. Raw results of $g$ compound/ $g$ total weight of distillate. 15 Table S 11. Raw results of $g$ compound/ $g$ total weight of distillate as obtained by the GC $\times$ GCFID analysis (continued). Orange font: gasoline range species, yellow: diesel range species, grey: AR range species. 16 Table S 12. Raw results of $\mathrm{g}$ compound/ $\mathrm{g}$ total weight of distillate as obtained by the GC $\times \mathrm{GC}$ FID analysis (continued) 17 Table S 13. Mass fraction of vacuum gas oil, diesel, gasoline, gas and coke lumps in distillate fraction 17 Table S 14. Alkenes mass fraction in distillate, vacuum residue and SCW-treated vacuum residue (reaction time $=90$ minutes) 18

\section{Batch reactor pressure profile}

The pressure profile in the batch reactor, for a representative 30 minute run is shown in Figure $\mathrm{S}$ 1. The reaction time includes the heat-up time of the reactor and until immeditely after quenching the reactor in water. 


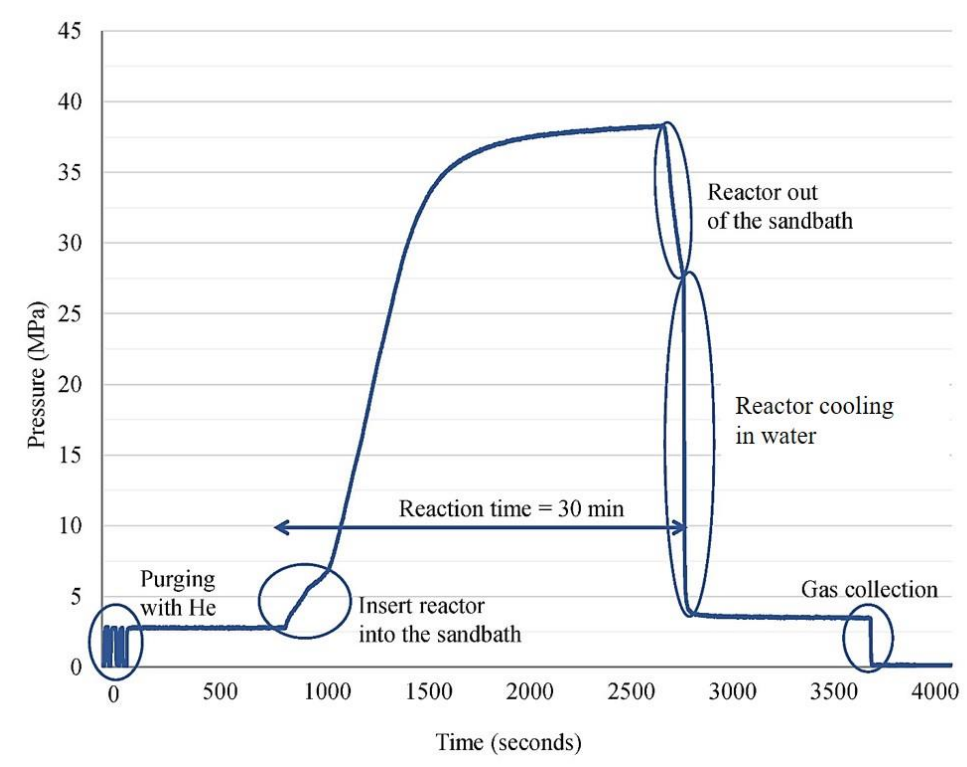

Figure $S$ 1. The pressure profile in the batch reactor for a representative 30 minute run.

2. GC $\times$ GC Analysis of Reactor Residue and Upgraded Oil

GC $\times$ GC-FID was used for compositional analysis of the upgraded oil and reactor residue. Figure S 1 shows the GC $\times$ GC spectra of the feed, upgraded oil and reactor residue obtained after SCW treatment (time = 30 minutes), Figure S 1 (a), obtained from analysis of the vacuum residue fraction fed to the SCW reactor, shows only a few aliphatic compounds, ranging from $\mathrm{C}_{18}-\mathrm{C}_{40}$, and a few aromatic compounds. The chromatogram of the upgraded oil fraction, Figure S 1 (b), shows drastic differences when compared to untreated vacuum residue, Figure S 1(a). Specifically, the concentrations of the GC-analyzable aliphatics, alkylaromatics, alkylnaphthalenes and polycyclic aromatic hydrocarbon are greater in the SCW-treated vacuum residue fraction. The spectra of reactor residue is similar as that of the upgraded oil (shown in Figure $S$ 1(c)). One prominent difference in the spectra of upgraded oil and reactor residue is in the low volatility region, corresponding to GC elution times in the range of 0-10 minutes. The reactor residue chromatogram does not have any peaks in the low-volatility region, probably due to loss of low boiling point 
components during evaporation of the solvent (DCM). The mass fractions of hydrocarbon components in the upgraded oil and reactor residue are plotted in Figure S 3. Figure S 3 shows that the mass fraction of aliphatics, alkylbenzenes, multi-ring species and GC-unquantified mass fraction are similar between upgraded oil and reactor residue. The GC-unquantified mass fraction represents the higher boiling point components in the oil which were not vaporized at GC inlet and therefore not detected.

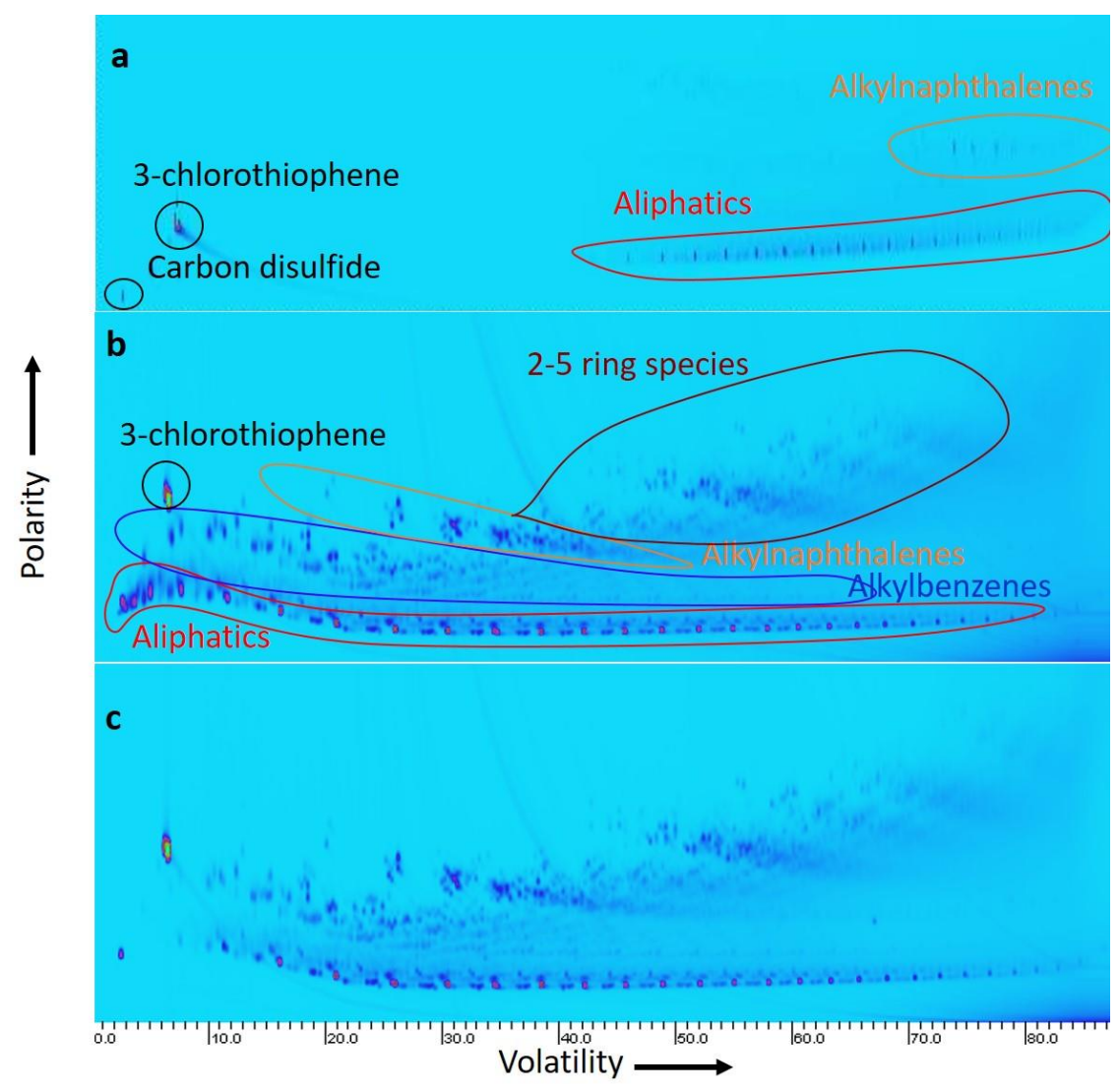

Figure $S$ 2. GC $\times G C$ spectra of (a) vacuum residue (b) upgraded oil and (c) reactor residue in vacuum residue and $S C W$ experiment (time $=30$ minutes). Carbon disulfide was used as diluent and 3-chlorothiophene was used as an external standard. 


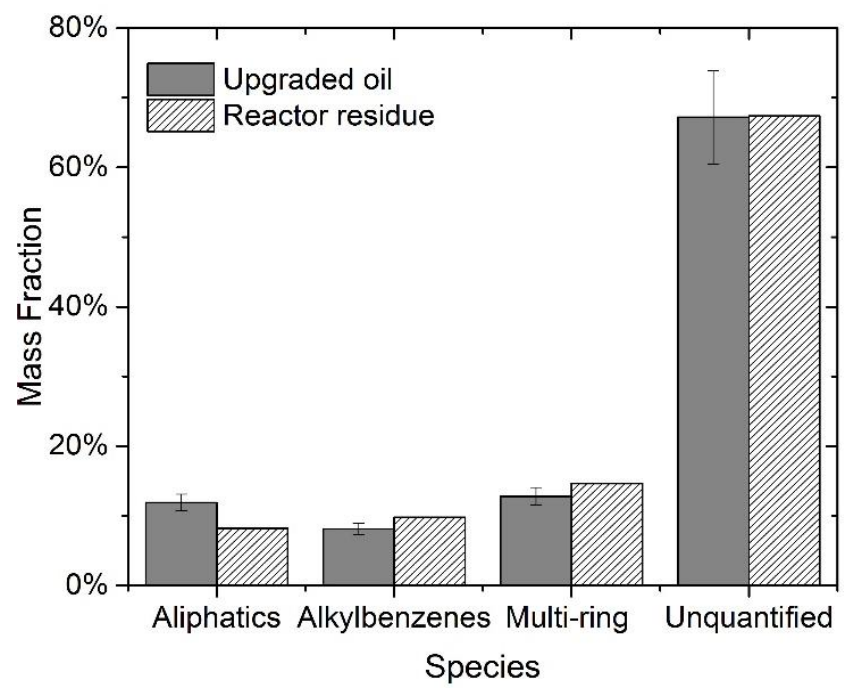

Figure S 3. Mass fraction of aliphatics, alkylbenzenes, multi-ring species and unquantified fraction in upgraded oil and reactor residue from vacuum residue and $S C W$ experiments (time $=30$ minutes).

3. Proton NMR analysis of aqueous phase of crude upgrading experiments (reaction time $=30$ minutes)

The aqueous phase from the crude oil upgrading experiments (reaction time of 30 minutes) was analyzed using proton NMR on a Varian Inova-500 NMR spectrometer. For the NMR experiments, deuterium oxide was used as diluent and dimethyl sulfoxide was used as an internal standard. The delay time used was 2 seconds and the sample was analyzed for 100 scans. There is a slight shift in the spectra of water and dimethylsulfoxide. The NMR spectra (shown in Figure S 4) did not show any functional groups other than the peak of the internal standard (DMSO) and water, confirming that in the current crude oil upgrading experiments, no hydrocarbons were detectable in the water phase. This is consistent with prior experiments, which also failed to detect organics in the aqueous phase using other analytical techniques.[10,11] 


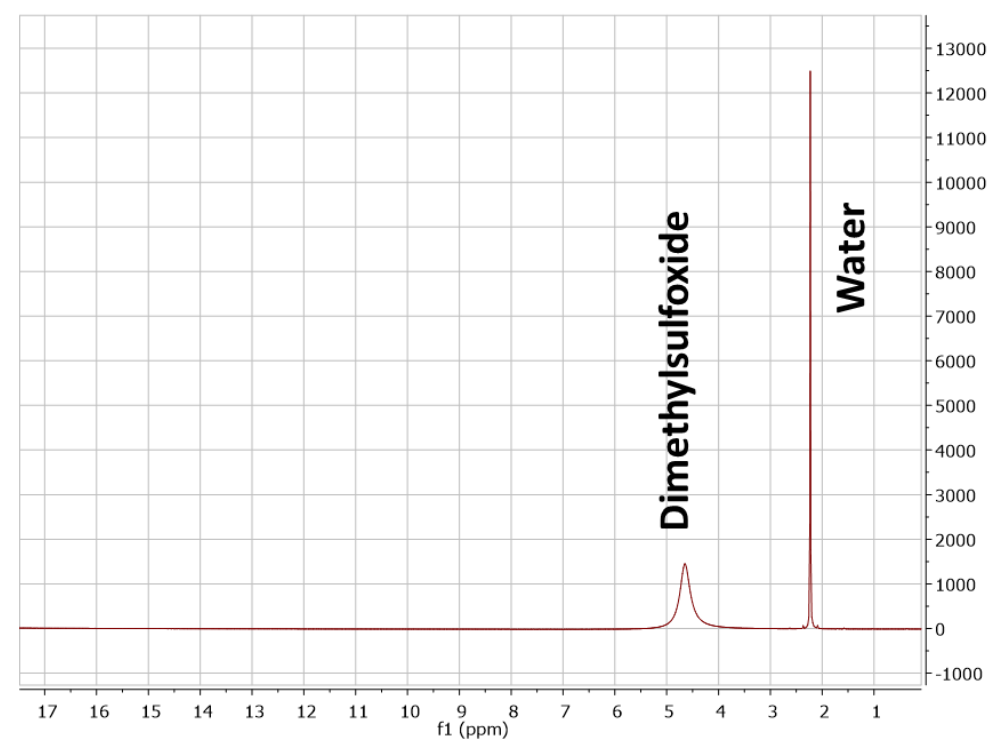

Figure S 4. Proton NMR spectra of aqueous phase obtained post-reaction for vacuum residue upgrading experiments (reaction time $=30$ minutes).

\section{GC $\times \mathrm{GC}$ calibrations}

The calibration mix used for obtaining the calibration factors for the various hydrocarbon classes consisted of alkanes (octane, decane, tetradecane, hexadecane), alkenes (1-octene, 1-decene, 1hexadecene), alkylbenzenes (toluene, ethylbenzene, styrene, butylbenzene, hexylbenzene) and polycyclic aromatic hydrocarbons (naphthalene, 2-methyl naphthalene) in mole fractions ranging from $6.25 \%$ to $0.025 \%$ in carbon disulfide. 3-Chlorothiophene was added as an internal standard to the mix. The calibration slopes of the compounds were calculated using exponential regression equations shown in Table S 1 . These equations were derived by fitting an exponential curve to mole fraction/signal of different class of compounds (alkanes, alkenes, alkylbenzenes, PAH etc.) as a function of carbon number. An example graph with exponential regression equation for alkanes is shown in Figure S 5. The $\mathrm{R}^{2}$ value determines how closely the function fits the particular set of experimental data. 
Table $S$ 1. Exponential regression equations for the determination of calibration factors (mole fraction/signal) based on the number of carbons, for alkanes, alkenes, alkylbenzenes and alkylnaphthalenes

\begin{tabular}{|l|c|l|}
\hline Group of compounds & GC $\times$ GC-FID equation & $\mathbf{R}^{\mathbf{2}}$ \\
\hline Alkanes & $y=7.08 \times 10^{-10} e^{-0.211 x}$ & 0.998 \\
\hline Alkenes & $y=8.29 \times 10^{-10} e^{-0.21 x}$ & 0.966 \\
\hline Alkylbenzenes & $y=2.71 \times 10^{-10} e^{-0.302 x}$ & 0.996 \\
\hline Alkylnaphthalenes & $y=6.65 \times 10^{-11} e^{-0.15 x}$ & 1.00 \\
\hline
\end{tabular}

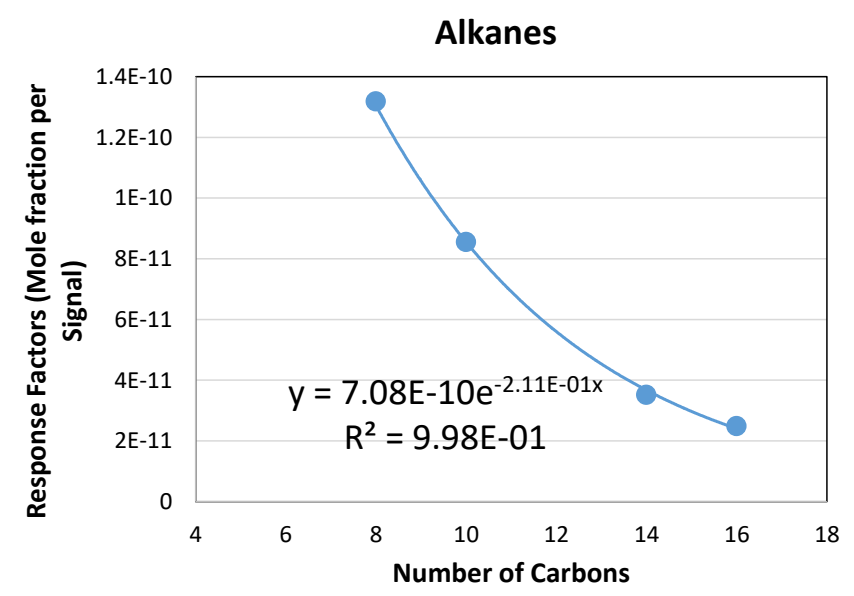

Figure S 5. GC $\times G C$-FID calibration factor of alkanes determined as a function of carbon number. The calibration factors for polycyclic aromatic hydrocarbons was determined through a single point calibration using 610 PAH Calibration Mix from Restek. The calibration mix consisted of 16 PAHs (acenaphthene, acenaphthylene, anthracene, benz(a)anthracene, benzo(a)pyrene, benzo(b)fluoranthene, benzo(k)fluoranthene, benzo(ghi)perylene, chrysene, dibenz(a,h)anthracene, fluoranthene, fluorene, indeno(1,2,3-cd)pyrene, naphthalene, phenanthrene and pyrene). The calibration factors of 3-6 ringed compounds were determined relative to naphthalene. The calibration factor of 3-6 ringed compounds was A x calibration factor of naphthalene, where A was 0.772 for 3-ring species, 0.872 for 4-ring species and 0.516 for 5-ring species. 
The mass fraction of species in the vacuum residue and upgraded oils (15-90 minutes) was determined using the below equations:

Moles of species in sample $=$

Peak volume $x$ calibration factor of species $x$ Moles of 3 -chlorothiophene in sample calibration factor of 3-chlorothiophene $x$ peak volume of 3-chlorothiophene

Mass fraction of species in sample $=$

$\frac{\text { moles of species in sample } x \text { molecular weight of species }}{\text { Mass of sample in } G C-\text { vial }} \times \frac{\text { mass of organic liquids }}{\text { mass of vaccum residue in batch reactor }(2 \mathrm{~g})}$

\section{GC×GC spectra of upgraded oil and species information}

The GC $\times$ GC spectra of upgraded oil obtained post-reaction time of 75 minutes is shown in Figure S 6. Alkanes ranging from $C_{6}$ to $C_{30}$ and alkenes ranging from $C_{9}$ to $C_{21}$ were identified in the upgraded oil. The alkanes and alkenes were predominantly straight chain compounds, with minor amounts of branched and cyclic alkanes and alkenes. In addition to alkanes and alkenes, aromatics such as alkylbenzenes, alkylnaphthalenes, 2-ring, 3-ring and 4-ring aromatics were also observed in the upgraded oil. The retention times of 2-4 ring aromatics were determined from the $610 \mathrm{PAH}$ calibration mix. It was not possible to identify the structure of the 2-4 ring compounds. 


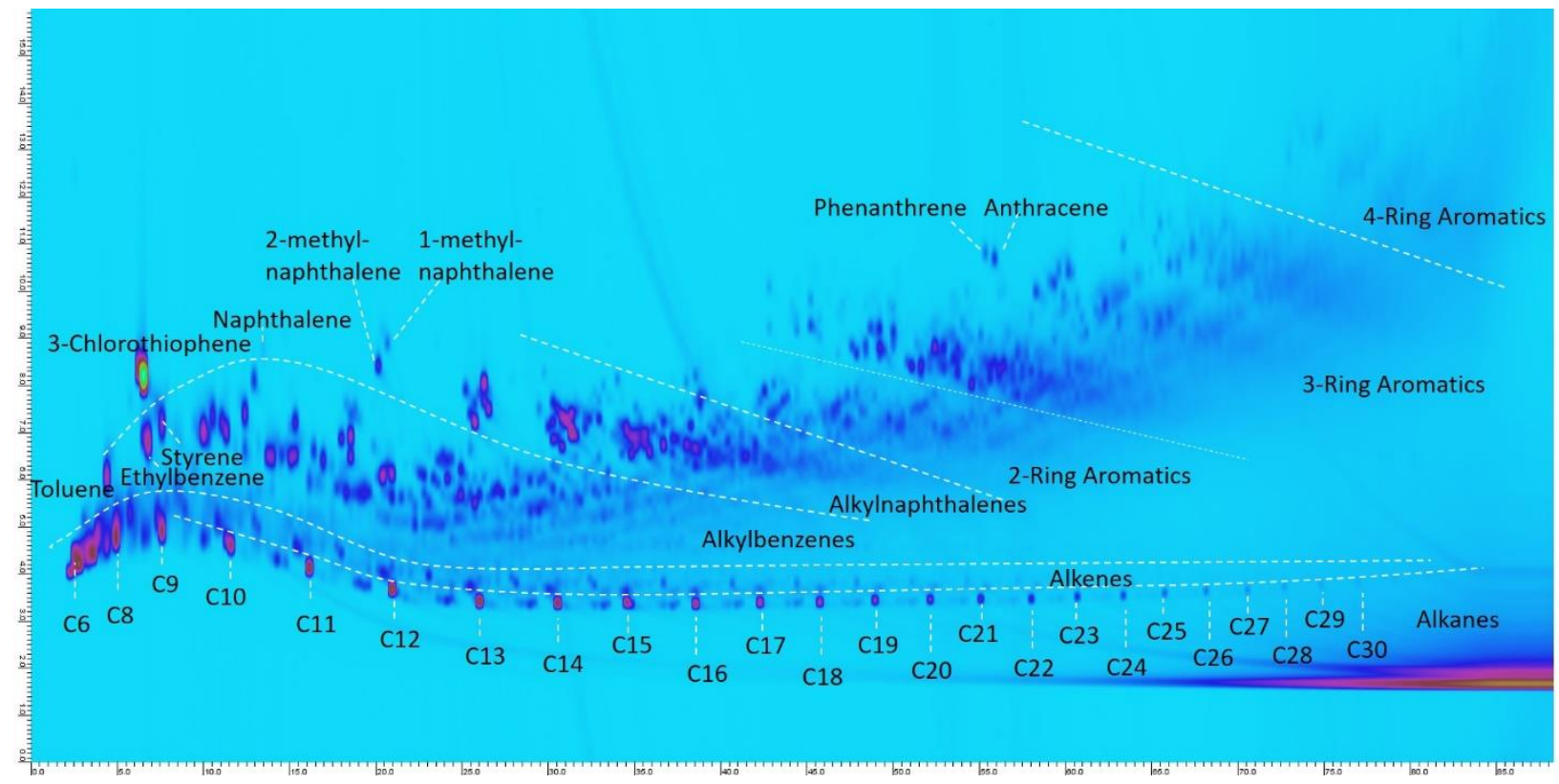

Figure S 6. GC $\times G C$ spectra of upgraded oil (75 minute run), showing the allocation of major hydrocarbon classes and species.

6. Elemental analysis of vacuum residue

The CHN analysis was performed using PerkinElmer 2400 Series II CHNS/O Analyzer. O was determined using Thermo Finnigan FlashEA Elemental Analyzer. The sulfur wt $\%$ was measured by X-ray fluorescence (XRF) using a Horiba instrument.

Table S 2. Elemental analysis of vacuum residue

\begin{tabular}{|l|r|}
\hline Element & Wt. \% \\
\hline C & 84 \\
\hline H & 10.91 \\
\hline N & $<0.5$ \\
\hline O & 0.92 \\
\hline S & $\sim 4.2$ \\
\hline
\end{tabular}


7. GC $\times \mathrm{GC}$ analysis of vacuum residue and upgraded oil at varied reaction times

Table $S$ 3. Raw results of $g$ compound/g total weight vacuum residue as obtained by the GC-FID (gas phase) and $G C \times G C-F I D$ analysis (liquid phase).Blue font: gas phase species, orange: gasoline range species, yellow: diesel range species, grey: AR range species.

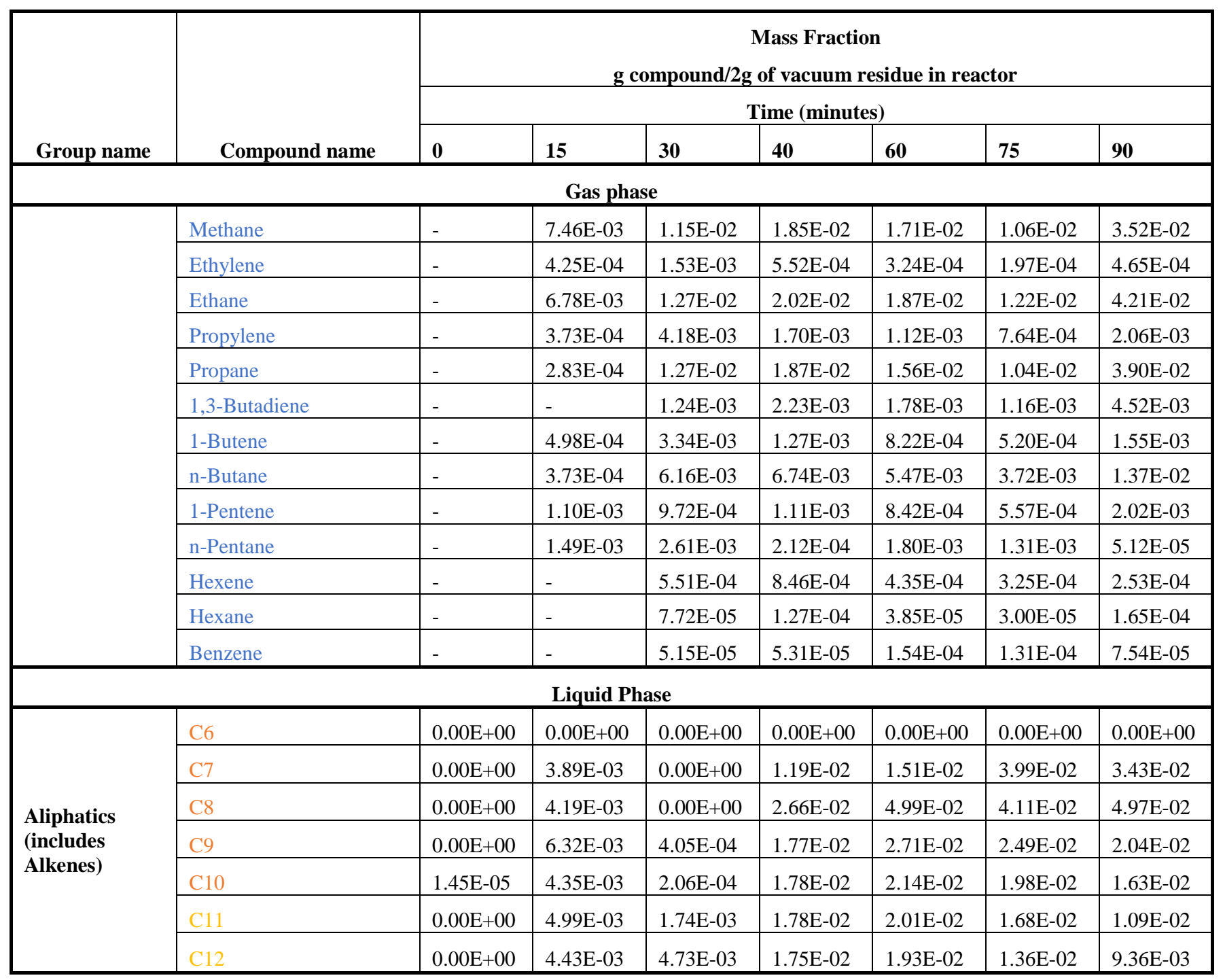


Table S4. Raw results of $g$ compound/g total weight vacuum residue as obtained by $G C \times G C-F I D$ analysis (continued). Orange font: gasoline range species, yellow: diesel range species, grey: AR range species

\begin{tabular}{|c|c|c|c|c|c|c|c|c|}
\hline \multirow[b]{3}{*}{ Group name } & \multirow[b]{3}{*}{ Compound name } & \multicolumn{7}{|c|}{$\begin{array}{c}\text { Mass Fraction } \\
\mathrm{g} \text { compound/2g of vacuum residue in reactor }\end{array}$} \\
\hline & & \multicolumn{7}{|c|}{ Time (minutes) } \\
\hline & & 0 & 15 & 30 & 40 & 60 & 75 & 90 \\
\hline \multirow{24}{*}{$\begin{array}{l}\text { Aliphatics } \\
\text { (includes } \\
\text { alkenes) }\end{array}$} & $\mathrm{C} 13$ & $0.00 \mathrm{E}+00$ & $4.74 \mathrm{E}-03$ & $7.14 \mathrm{E}-03$ & $1.57 \mathrm{E}-02$ & $1.39 \mathrm{E}-02$ & $9.96 \mathrm{E}-03$ & $9.01 \mathrm{E}-03$ \\
\hline & $\mathrm{C} 14$ & $0.00 \mathrm{E}+00$ & $4.15 \mathrm{E}-03$ & $7.00 \mathrm{E}-03$ & $1.17 \mathrm{E}-02$ & $1.09 \mathrm{E}-02$ & 7.09E-03 & $5.28 \mathrm{E}-03$ \\
\hline & $\mathrm{C} 15$ & $0.00 \mathrm{E}+00$ & $3.89 \mathrm{E}-03$ & $6.21 \mathrm{E}-03$ & $1.02 \mathrm{E}-02$ & 7.44E-03 & $5.49 \mathrm{E}-03$ & $3.48 \mathrm{E}-03$ \\
\hline & $\mathrm{C} 16$ & $0.00 \mathrm{E}+00$ & $3.67 \mathrm{E}-03$ & $5.61 \mathrm{E}-03$ & $6.90 \mathrm{E}-03$ & 4.72E-03 & $2.55 \mathrm{E}-03$ & $1.92 \mathrm{E}-03$ \\
\hline & $\mathrm{C} 17$ & $0.00 \mathrm{E}+00$ & $2.51 \mathrm{E}-03$ & $4.09 \mathrm{E}-03$ & $5.34 \mathrm{E}-03$ & $3.98 \mathrm{E}-03$ & $2.23 \mathrm{E}-03$ & $1.55 \mathrm{E}-03$ \\
\hline & $\mathrm{C} 18$ & $1.86 \mathrm{E}-04$ & $2.31 \mathrm{E}-03$ & $2.94 \mathrm{E}-03$ & $4.47 \mathrm{E}-03$ & 2.93E-03 & $1.59 \mathrm{E}-03$ & $9.81 \mathrm{E}-04$ \\
\hline & $\mathrm{C} 19$ & 7.61E-04 & $2.30 \mathrm{E}-03$ & $2.55 \mathrm{E}-03$ & $4.02 \mathrm{E}-03$ & $2.35 \mathrm{E}-03$ & $1.21 \mathrm{E}-03$ & $8.05 \mathrm{E}-04$ \\
\hline & $\mathrm{C} 20$ & $1.66 \mathrm{E}-03$ & $2.03 \mathrm{E}-03$ & $2.10 \mathrm{E}-03$ & $2.70 \mathrm{E}-03$ & $1.47 \mathrm{E}-03$ & $7.89 \mathrm{E}-04$ & $5.82 \mathrm{E}-04$ \\
\hline & $\mathrm{C} 21$ & $2.65 \mathrm{E}-03$ & $2.26 \mathrm{E}-03$ & $1.98 \mathrm{E}-03$ & $1.57 \mathrm{E}-03$ & $1.02 \mathrm{E}-03$ & 4.91E-04 & $3.16 \mathrm{E}-04$ \\
\hline & $\mathrm{C} 22$ & $2.28 \mathrm{E}-03$ & $2.15 \mathrm{E}-03$ & $1.22 \mathrm{E}-03$ & $1.56 \mathrm{E}-03$ & $6.15 \mathrm{E}-04$ & $3.40 \mathrm{E}-04$ & $2.65 \mathrm{E}-04$ \\
\hline & $\mathrm{C} 23$ & $2.32 \mathrm{E}-03$ & $1.76 \mathrm{E}-03$ & $1.10 \mathrm{E}-03$ & $9.21 \mathrm{E}-04$ & $3.64 \mathrm{E}-04$ & $1.84 \mathrm{E}-04$ & $1.57 \mathrm{E}-04$ \\
\hline & $\mathrm{C} 24$ & $2.07 \mathrm{E}-03$ & $1.65 \mathrm{E}-03$ & $1.02 \mathrm{E}-03$ & $8.71 \mathrm{E}-04$ & $3.90 \mathrm{E}-04$ & $1.77 \mathrm{E}-04$ & $2.57 \mathrm{E}-04$ \\
\hline & $\mathrm{C} 25$ & $1.86 \mathrm{E}-03$ & $1.33 \mathrm{E}-03$ & $8.53 \mathrm{E}-04$ & 4.69E-04 & $1.66 \mathrm{E}-04$ & $7.28 \mathrm{E}-05$ & $1.16 \mathrm{E}-04$ \\
\hline & $\mathrm{C} 26$ & $1.55 \mathrm{E}-03$ & $1.10 \mathrm{E}-03$ & $6.10 \mathrm{E}-04$ & $7.09 \mathrm{E}-04$ & $1.83 \mathrm{E}-04$ & $8.19 \mathrm{E}-05$ & $1.29 \mathrm{E}-04$ \\
\hline & $\mathrm{C} 27$ & $1.53 \mathrm{E}-03$ & $9.39 \mathrm{E}-04$ & $4.28 \mathrm{E}-04$ & 4.44E-04 & $1.41 \mathrm{E}-04$ & $9.01 \mathrm{E}-05$ & $1.23 \mathrm{E}-04$ \\
\hline & $\mathrm{C} 28$ & $1.23 \mathrm{E}-03$ & 7.41E-04 & $3.18 \mathrm{E}-04$ & $2.07 \mathrm{E}-04$ & $1.37 \mathrm{E}-04$ & $9.53 \mathrm{E}-05$ & $8.65 \mathrm{E}-05$ \\
\hline & $\mathrm{C} 29$ & $1.02 \mathrm{E}-03$ & $6.15 \mathrm{E}-04$ & $2.34 \mathrm{E}-04$ & $2.42 \mathrm{E}-04$ & $1.26 \mathrm{E}-04$ & $3.41 \mathrm{E}-05$ & $3.97 \mathrm{E}-05$ \\
\hline & $\mathrm{C} 30$ & 7.91E-04 & 4.62E-04 & $1.68 \mathrm{E}-04$ & $1.61 \mathrm{E}-04$ & 5.17E-05 & $7.82 \mathrm{E}-05$ & $1.69 \mathrm{E}-04$ \\
\hline & $\mathrm{C} 31$ & $6.54 \mathrm{E}-04$ & 4.84E-04 & $1.60 \mathrm{E}-04$ & $2.08 \mathrm{E}-04$ & $9.06 \mathrm{E}-05$ & $1.10 \mathrm{E}-04$ & $1.28 \mathrm{E}-05$ \\
\hline & $\mathrm{C} 32$ & $5.56 \mathrm{E}-04$ & $3.38 \mathrm{E}-04$ & $1.00 \mathrm{E}-04$ & $2.66 \mathrm{E}-04$ & $0.00 \mathrm{E}+00$ & $0.00 \mathrm{E}+00$ & $0.00 \mathrm{E}+00$ \\
\hline & $\mathrm{C} 33$ & $4.48 \mathrm{E}-04$ & $2.43 \mathrm{E}-04$ & 7.63E-05 & $0.00 \mathrm{E}+00$ & $0.00 \mathrm{E}+00$ & $0.00 \mathrm{E}+00$ & $0.00 \mathrm{E}+00$ \\
\hline & $\mathrm{C} 34$ & $3.48 \mathrm{E}-04$ & $2.51 \mathrm{E}-04$ & 4.91E-05 & $0.00 \mathrm{E}+00$ & $0.00 \mathrm{E}+00$ & $0.00 \mathrm{E}+00$ & $0.00 \mathrm{E}+00$ \\
\hline & $\mathrm{C} 35$ & $2.57 \mathrm{E}-04$ & $1.68 \mathrm{E}-04$ & 3.03E-05 & $0.00 \mathrm{E}+00$ & $0.00 \mathrm{E}+00$ & $0.00 \mathrm{E}+00$ & $0.00 \mathrm{E}+00$ \\
\hline & $\mathrm{C} 36$ & 8.97E-05 & $1.08 \mathrm{E}-04$ & $2.47 \mathrm{E}-05$ & $0.00 \mathrm{E}+00$ & $0.00 \mathrm{E}+00$ & $0.00 \mathrm{E}+00$ & $0.00 \mathrm{E}+00$ \\
\hline
\end{tabular}


Table $S$ 5. Raw results of $g$ compound/ $g$ total weight vacuum residue as obtained by $G C \times G C$-FID analysis (continued). Orange font: gasoline range species, yellow: diesel range species, grey: AR range species

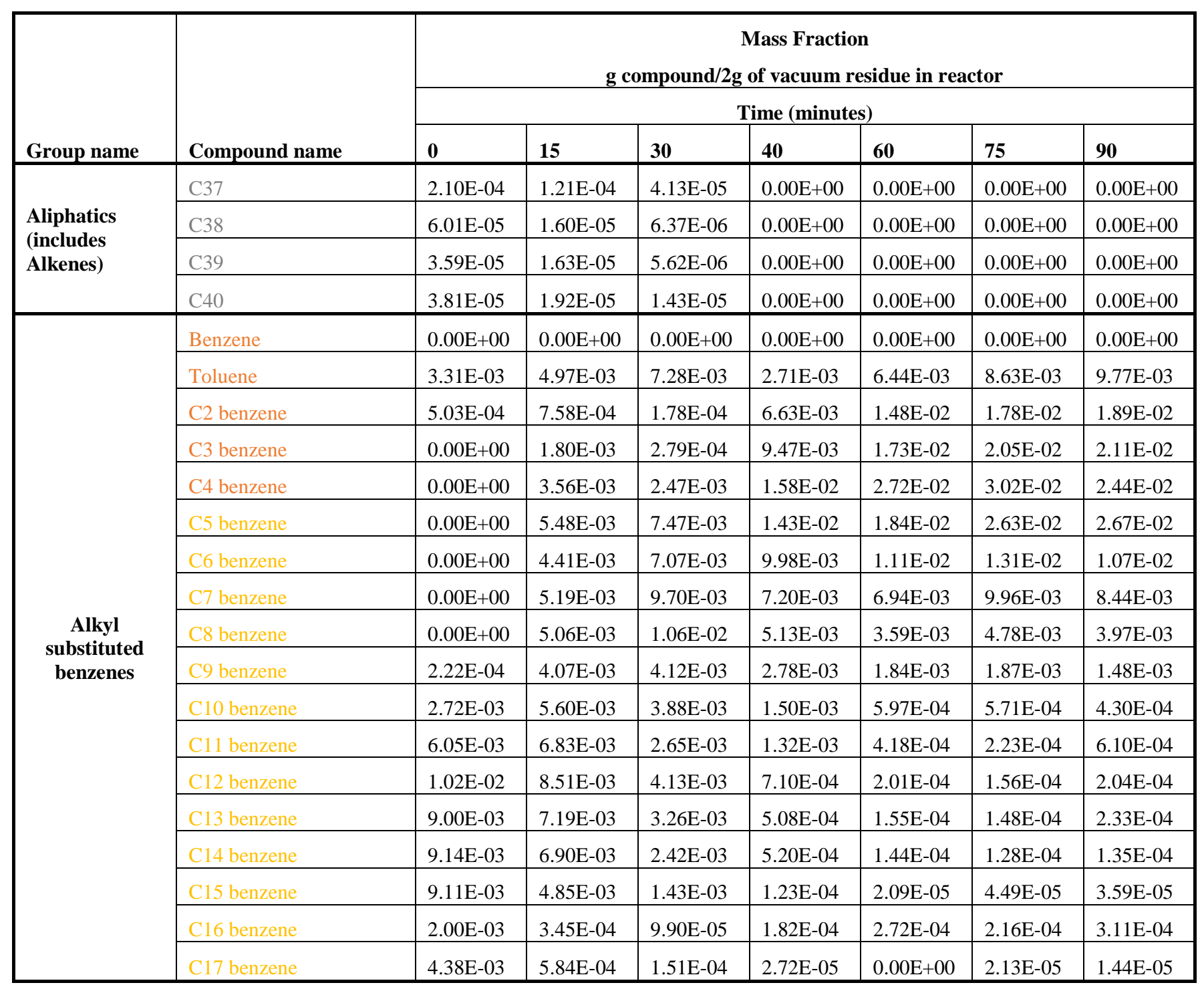


Table $S$ 6. Raw results of $g$ compound/g total weight vacuum residue as obtained by $G C \times G C-F I D$ analysis (continued). Orange font: gasoline range species, yellow: diesel range species, grey: AR range species.

\begin{tabular}{|c|c|c|c|c|c|c|c|c|}
\hline \multirow{3}{*}{ Group name } & \multirow[b]{3}{*}{ Compound name } & \multirow{2}{*}{\multicolumn{7}{|c|}{\begin{tabular}{c} 
Mass Fraction \\
g compound/2g of vacuum residue in rea \\
\multicolumn{2}{|c|}{ Time (minutes) } \\
\end{tabular}}} \\
\hline & & & & & & & & \\
\hline & & $\mathbf{0}$ & 15 & 30 & 40 & 60 & 75 & 90 \\
\hline $\begin{array}{l}\text { Alkyl } \\
\text { substituted } \\
\text { benzenes }\end{array}$ & C18 benzene & $0.00 \mathrm{E}+00$ & $0.00 \mathrm{E}+00$ & $0.00 \mathrm{E}+00$ & $0.00 \mathrm{E}+00$ & $0.00 \mathrm{E}+00$ & $0.00 \mathrm{E}+00$ & $0.00 \mathrm{E}+00$ \\
\hline \multirow{15}{*}{$\begin{array}{l}\text { Alkyl } \\
\text { substituted } \\
\text { naphthalenes }\end{array}$} & Naphthalene & $0.00 \mathrm{E}+00$ & $1.22 \mathrm{E}-04$ & $0.00 \mathrm{E}+00$ & $3.11 \mathrm{E}-04$ & $1.00 \mathrm{E}-03$ & $1.05 \mathrm{E}-03$ & $1.24 \mathrm{E}-03$ \\
\hline & C1 naphthalene & $0.00 \mathrm{E}+00$ & $7.66 \mathrm{E}-04$ & $1.67 \mathrm{E}-03$ & $3.37 \mathrm{E}-03$ & $5.66 \mathrm{E}-03$ & $8.73 \mathrm{E}-03$ & $9.31 \mathrm{E}-03$ \\
\hline & C2 naphthalene & $0.00 \mathrm{E}+00$ & $1.31 \mathrm{E}-03$ & $3.71 \mathrm{E}-03$ & $7.50 \mathrm{E}-03$ & $1.17 \mathrm{E}-02$ & $1.54 \mathrm{E}-02$ & $1.42 \mathrm{E}-02$ \\
\hline & C3 naphthalene & $0.00 \mathrm{E}+00$ & $2.16 \mathrm{E}-03$ & 5.03E-03 & $9.42 \mathrm{E}-03$ & $1.13 \mathrm{E}-02$ & $1.72 \mathrm{E}-02$ & $1.63 \mathrm{E}-02$ \\
\hline & C4 naphthalene & $0.00 \mathrm{E}+00$ & $2.46 \mathrm{E}-03$ & $4.39 \mathrm{E}-03$ & $3.55 \mathrm{E}-03$ & $6.27 \mathrm{E}-03$ & 7.77E-03 & $6.57 \mathrm{E}-03$ \\
\hline & C5 naphthalene & $5.55 \mathrm{E}-05$ & $2.03 \mathrm{E}-03$ & $4.74 \mathrm{E}-03$ & $3.35 \mathrm{E}-03$ & $5.93 \mathrm{E}-03$ & $5.95 \mathrm{E}-03$ & $5.12 \mathrm{E}-03$ \\
\hline & C6 naphthalene & $1.64 \mathrm{E}-03$ & 4.93E-03 & $7.96 \mathrm{E}-03$ & $5.43 \mathrm{E}-03$ & $4.78 \mathrm{E}-03$ & $5.30 \mathrm{E}-03$ & $4.66 \mathrm{E}-03$ \\
\hline & C7 naphthalene & $4.76 \mathrm{E}-03$ & 4.73E-03 & 4.97E-03 & $2.51 \mathrm{E}-03$ & $2.11 \mathrm{E}-03$ & $1.90 \mathrm{E}-03$ & $1.22 \mathrm{E}-03$ \\
\hline & C8 naphthalene & $7.35 \mathrm{E}-03$ & $5.18 \mathrm{E}-03$ & $3.78 \mathrm{E}-03$ & $1.81 \mathrm{E}-03$ & $1.36 \mathrm{E}-03$ & 4.43E-04 & $0.00 \mathrm{E}+00$ \\
\hline & C9 naphthalene & $1.08 \mathrm{E}-02$ & $7.44 \mathrm{E}-03$ & 4.87E-03 & $1.74 \mathrm{E}-03$ & $6.19 \mathrm{E}-04$ & $0.00 \mathrm{E}+00$ & $0.00 \mathrm{E}+00$ \\
\hline & C10 naphthalene & 8.34E-03 & $6.93 \mathrm{E}-03$ & $3.15 \mathrm{E}-03$ & $8.27 \mathrm{E}-05$ & $0.00 \mathrm{E}+00$ & $0.00 \mathrm{E}+00$ & $2.10 \mathrm{E}-04$ \\
\hline & C11 naphthalene & $9.27 \mathrm{E}-03$ & $6.15 \mathrm{E}-03$ & $2.56 \mathrm{E}-03$ & 8.62E-04 & $4.96 \mathrm{E}-05$ & $2.40 \mathrm{E}-04$ & 8.44E-04 \\
\hline & C12 naphthalene & $1.17 \mathrm{E}-02$ & $5.94 \mathrm{E}-03$ & $9.20 \mathrm{E}-04$ & $1.52 \mathrm{E}-04$ & 4.27E-04 & $1.73 \mathrm{E}-04$ & $0.00 \mathrm{E}+00$ \\
\hline & C13 naphthalene & $2.35 \mathrm{E}-02$ & $9.07 \mathrm{E}-03$ & $1.65 \mathrm{E}-03$ & 3.97E-04 & $4.82 \mathrm{E}-04$ & 4.98E-04 & $7.38 \mathrm{E}-04$ \\
\hline & C14 naphthalene & $1.85 \mathrm{E}-02$ & 4.97E-03 & $7.52 \mathrm{E}-04$ & $0.00 \mathrm{E}+00$ & $0.00 \mathrm{E}+00$ & $0.00 \mathrm{E}+00$ & $0.00 \mathrm{E}+00$ \\
\hline \multirow{4}{*}{ ring aromatics } & 2-ring & $1.95 \mathrm{E}-03$ & $6.46 \mathrm{E}-03$ & $1.43 \mathrm{E}-02$ & $3.36 \mathrm{E}-02$ & $3.43 \mathrm{E}-02$ & $4.28 \mathrm{E}-02$ & 4.13E-02 \\
\hline & 3-ring & $1.34 \mathrm{E}-02$ & $1.75 \mathrm{E}-02$ & $3.69 \mathrm{E}-02$ & $7.63 \mathrm{E}-02$ & $6.26 \mathrm{E}-02$ & 7.52E-02 & $6.74 \mathrm{E}-02$ \\
\hline & 4-ring & $1.92 \mathrm{E}-03$ & $6.06 \mathrm{E}-03$ & $6.82 \mathrm{E}-03$ & $5.37 \mathrm{E}-02$ & $9.93 \mathrm{E}-02$ & $1.30 \mathrm{E}-01$ & $1.28 \mathrm{E}-01$ \\
\hline & 5-ring & $3.46 \mathrm{E}-03$ & $0.00 \mathrm{E}+00$ & $7.29 \mathrm{E}-03$ & $0.00 \mathrm{E}+00$ & $0.00 \mathrm{E}+00$ & $2.80 \mathrm{E}-02$ & 4.35E-02 \\
\hline
\end{tabular}


Table $S$ 7. Raw results of $g$ compound/g total weight vacuum residue as obtained by $G C \times G C-F I D$ analysis (continued)

\begin{tabular}{|c|c|c|c|c|c|c|c|c|}
\hline & \multirow[b]{3}{*}{ Parameter } & \multicolumn{7}{|c|}{$\begin{array}{c}\text { Mass Fraction } \\
\mathrm{g} \text { compound } / 2 \mathrm{~g} \text { of vacuum residue in reactor }\end{array}$} \\
\hline & & \multicolumn{7}{|c|}{ Time (minutes) } \\
\hline & & 0 & 15 & 30 & 40 & 60 & 75 & 90 \\
\hline \multirow{4}{*}{$\begin{array}{l}\text { GC observed } \\
\text { mass fraction } \\
\text { and \% Carbon } \\
\text { Recovery }\end{array}$} & $\begin{array}{l}\text { Total GC observed mass fraction } \\
(\mathrm{g} / \mathrm{g} \%)\end{array}$ & $19.6 \%$ & $25.8 \%$ & $29.3 \%$ & $53.3 \%$ & $62.5 \%$ & $70.6 \%$ & $77.6 \%$ \\
\hline & Total GC observed mass $(\mathrm{g})$ & $1.99 \mathrm{E}-02$ & $1.49 \mathrm{E}-02$ & 7.74E-03 & $2.51 \mathrm{E}-02$ & $2.20 \mathrm{E}-02$ & 3.65E-02 & 3.95E-02 \\
\hline & Mass of oil sample in vial $(\mathrm{g})$ & $1.02 \mathrm{E}-01$ & $5.86 \mathrm{E}-02$ & $2.50 \mathrm{E}-02$ & $4.50 \mathrm{E}-02$ & 3.17E-02 & 4.47E-02 & $4.32 \mathrm{E}-02$ \\
\hline & $\%$ Carbon recovery & $19.5 \%$ & $25.4 \%$ & $31.0 \%$ & $55.9 \%$ & $69.5 \%$ & $81.7 \%$ & $91.5 \%$ \\
\hline
\end{tabular}

Table S 8. Mass fraction of vacuum gas oil, diesel, gasoline, gas and coke lumps in vacuum residue $+S C W$ experiments

\begin{tabular}{|c|c|c|c|c|c|c|c|c|}
\hline \multirow[b]{2}{*}{ Lump Name } & \multirow{2}{*}{$\begin{array}{l}\text { Carbon } \\
\text { Number } \\
\end{array}$} & \multicolumn{7}{|c|}{$\begin{array}{c}\text { Reaction time (minutes) } \\
\text { Mass Fraction } \\
\end{array}$} \\
\hline & & $\mathbf{0}$ & 15 & 30 & 40 & 60 & 75 & 90 \\
\hline Gas & $\mathrm{C} 1$ to $\mathrm{C} 6$ & $0.0 \%$ & $1.9 \%$ & $5.8 \%$ & $7.2 \%$ & $6.4 \%$ & $4.2 \%$ & $14.1 \%$ \\
\hline Gasoline & $\mathrm{C} 6-\mathrm{C} 10$ & $0.6 \%$ & $3.6 \%$ & $2.5 \%$ & $14.3 \%$ & $21.4 \%$ & $24.7 \%$ & $23.7 \%$ \\
\hline Diesel & $\mathrm{C} 11-\mathrm{C} 23$ & $15.9 \%$ & $18.9 \%$ & $20.6 \%$ & $31.5 \%$ & $34.5 \%$ & $41.7 \%$ & $39.6 \%$ \\
\hline Coke & & $0.0 \%$ & $4.2 \%$ & $8.4 \%$ & $10.2 \%$ & $12.0 \%$ & $14.1 \%$ & $16.5 \%$ \\
\hline $\begin{array}{l}\mathrm{AR}=1-\text {-Gas-Gasoline-Diesel- } \\
\text { Coke }\end{array}$ & & $83.5 \%$ & $71.4 \%$ & $62.7 \%$ & $36.8 \%$ & $25.6 \%$ & $15.3 \%$ & $6.0 \%$ \\
\hline Total & & $100.0 \%$ & $100.0 \%$ & $100.0 \%$ & $100.0 \%$ & $100.0 \%$ & $100.0 \%$ & $100.0 \%$ \\
\hline
\end{tabular}


8. GC $\times \mathrm{GC}$ Analysis of Distillate fraction

Table S 9. Raw results of $g$ compound/ $g$ total weight of distillate.

\begin{tabular}{|c|c|c|}
\hline Group name & Compound name & $\begin{array}{c}\text { Mass Fraction } \\
\text { g compound/2g of distillate }\end{array}$ \\
\hline \multirow{35}{*}{ Aliphatics (includes Alkenes) } & C6 & $0.00 \mathrm{E}+00$ \\
\hline & $\mathrm{C} 7$ & $5.52 \mathrm{E}-03$ \\
\hline & $\mathrm{C} 8$ & 4.29E-02 \\
\hline & C9 & 7.69E-02 \\
\hline & $\mathrm{C} 10$ & $5.71 \mathrm{E}-02$ \\
\hline & $\mathrm{C} 11$ & $6.09 \mathrm{E}-02$ \\
\hline & $\mathrm{C} 12$ & $6.64 \mathrm{E}-02$ \\
\hline & $\mathrm{C} 13$ & $6.95 \mathrm{E}-02$ \\
\hline & $\mathrm{C} 14$ & $5.88 \mathrm{E}-02$ \\
\hline & $\mathrm{C} 15$ & 4.45E-02 \\
\hline & C16 & 4.08E-02 \\
\hline & C17 & $1.26 \mathrm{E}-02$ \\
\hline & C18 & 4.17E-02 \\
\hline & $\mathrm{C} 19$ & $1.27 \mathrm{E}-02$ \\
\hline & $\mathrm{C} 20$ & $9.90 \mathrm{E}-03$ \\
\hline & $\mathrm{C} 21$ & $6.55 \mathrm{E}-03$ \\
\hline & $\mathrm{C} 22$ & $3.29 \mathrm{E}-03$ \\
\hline & $\mathrm{C} 23$ & $1.69 \mathrm{E}-03$ \\
\hline & $\mathrm{C} 24$ & $9.44 \mathrm{E}-04$ \\
\hline & $\mathrm{C} 25$ & $6.27 \mathrm{E}-04$ \\
\hline & $\mathrm{C} 26$ & $3.33 \mathrm{E}-04$ \\
\hline & $\mathrm{C} 27$ & $1.29 \mathrm{E}-04$ \\
\hline & $\mathrm{C} 28$ & $2.34 \mathrm{E}-04$ \\
\hline & $\mathrm{C} 29$ & $2.58 \mathrm{E}-05$ \\
\hline & $\mathrm{C} 30$ & $1.44 \mathrm{E}-04$ \\
\hline & $\mathrm{C} 31$ & $0.00 \mathrm{E}+00$ \\
\hline & $\mathrm{C} 32$ & $0.00 \mathrm{E}+00$ \\
\hline & $\mathrm{C} 33$ & $0.00 \mathrm{E}+00$ \\
\hline & $\mathrm{C} 34$ & $0.00 \mathrm{E}+00$ \\
\hline & $\mathrm{C} 35$ & $0.00 \mathrm{E}+00$ \\
\hline & $\mathrm{C} 36$ & $0.00 \mathrm{E}+00$ \\
\hline & C37 & $0.00 \mathrm{E}+00$ \\
\hline & $\mathrm{C} 38$ & $0.00 \mathrm{E}+00$ \\
\hline & $\mathrm{C} 39$ & $0.00 \mathrm{E}+00$ \\
\hline & $\mathrm{C} 40$ & $0.00 \mathrm{E}+00$ \\
\hline
\end{tabular}


Table S 10. Raw results of $g$ compound/ $g$ total weight of distillate as obtained by the $G C \times G C$ FID analysis (continued). Orange font: gasoline range species, yellow: diesel range species, grey: $A R$ range species.

\begin{tabular}{|c|c|c|}
\hline Group name & Compound name & $\begin{array}{l}\text { Mass Fraction } \\
\mathrm{g} \text { compound/2g of } \\
\text { distillate }\end{array}$ \\
\hline \multirow{19}{*}{ Alkyl substituted benzenes } & Benzene & $0.00 \mathrm{E}+00$ \\
\hline & Toluene & $3.00 \mathrm{E}-03$ \\
\hline & $\mathrm{C} 2$ benzene & 8.91E-03 \\
\hline & C3 benzene & $1.58 \mathrm{E}-02$ \\
\hline & C4 benzene & $2.36 \mathrm{E}-02$ \\
\hline & C5 benzene & $3.09 \mathrm{E}-02$ \\
\hline & C6 benzene & $1.92 \mathrm{E}-02$ \\
\hline & C7 benzene & $1.70 \mathrm{E}-02$ \\
\hline & C8 benzene & $1.54 \mathrm{E}-02$ \\
\hline & C9 benzene & $1.02 \mathrm{E}-02$ \\
\hline & C10 benzene & $6.20 \mathrm{E}-03$ \\
\hline & C11 benzene & $3.60 \mathrm{E}-03$ \\
\hline & C12 benzene & $1.28 \mathrm{E}-03$ \\
\hline & C13 benzene & $6.46 \mathrm{E}-04$ \\
\hline & C14 benzene & $2.29 \mathrm{E}-04$ \\
\hline & C15 benzene & $0.00 \mathrm{E}+00$ \\
\hline & C16 benzene & $0.00 \mathrm{E}+00$ \\
\hline & C17 benzene & $0.00 \mathrm{E}+00$ \\
\hline & C18 benzene & $0.00 \mathrm{E}+00$ \\
\hline \multirow{11}{*}{ Alkyl substituted naphthalenes } & Naphthalene & 1.45E-03 \\
\hline & C1 naphthalene & $1.17 \mathrm{E}-03$ \\
\hline & C2 naphthalene & $6.77 \mathrm{E}-03$ \\
\hline & C3 naphthalene & $1.13 \mathrm{E}-02$ \\
\hline & C4 naphthalene & $9.13 \mathrm{E}-03$ \\
\hline & C5 naphthalene & $7.91 \mathrm{E}-03$ \\
\hline & C6 naphthalene & $9.22 \mathrm{E}-03$ \\
\hline & C7 naphthalene & 4.74E-03 \\
\hline & C8 naphthalene & $2.71 \mathrm{E}-03$ \\
\hline & C9 naphthalene & $1.90 \mathrm{E}-03$ \\
\hline & C10 naphthalene & $1.93 \mathrm{E}-04$ \\
\hline
\end{tabular}


Table $S$ 11. Raw results of $g$ compound/ $g$ total weight of distillate as obtained by the $G C \times G C$ FID analysis (continued)

\begin{tabular}{|l|l|r|}
\hline \multirow{2}{*}{ Group name } & Compound name & \multicolumn{1}{c|}{$\begin{array}{c}\text { Mass Fraction } \\
\text { g compound/2g of } \\
\text { distillate }\end{array}$} \\
\hline \multirow{2}{*}{ ring aromatics } & 2-ring & $1.64 \mathrm{E}-02$ \\
\cline { 2 - 3 } & 3-ring & $1.63 \mathrm{E}-02$ \\
\cline { 2 - 3 } & 4-ring & $0.00 \mathrm{E}+00$ \\
\cline { 2 - 3 } & 5-ring & $0.00 \mathrm{E}+00$ \\
\hline Total GC observed mass fraction $(\mathrm{g} / \mathrm{g} \%)$ & & $85.9 \%$ \\
\hline Total GC observed mass $(\mathrm{g})$ & & $4.03 \mathrm{E}-02$ \\
\hline Mass of sample in vial $(\mathrm{g})$ & & $4.69 \mathrm{E}-02$ \\
\hline \% Carbon recovery & & $85.9 \%$ \\
\hline
\end{tabular}

Table S 12. Mass fraction of vacuum gas oil, diesel, gasoline, gas and coke lumps in distillate fraction

\begin{tabular}{|l|l|r|}
\hline Lump Name & $\begin{array}{l}\text { Carbon } \\
\text { Number }\end{array}$ & \multicolumn{1}{l|}{$\begin{array}{l}\text { Mass } \\
\text { Fraction }\end{array}$} \\
\hline Gas & C1 to C6 & $0.0 \%$ \\
\hline Gasoline & C6-C10 & $25.2 \%$ \\
\hline Diesel & C11-C23 & $60.5 \%$ \\
\hline Coke & & $0.0 \%$ \\
\hline AR =1-Gas-Gasoline-Diesel-Coke & & $14.3 \%$ \\
\hline Total & & $100.0 \%$ \\
\hline
\end{tabular}


9. Alkenes mass fraction in distillate, vacuum residue and SCW-treated vacuum residue

Table S 13. Alkenes mass fraction in distillate, vacuum residue and SCW-treated vacuum residue (reaction time $=90$ minutes)

\begin{tabular}{|c|c|c|c|c|}
\hline \multirow{3}{*}{$\begin{array}{l}\text { Group } \\
\text { name }\end{array}$} & \multirow{3}{*}{$\begin{array}{l}\text { Compound } \\
\text { name }\end{array}$} & \multicolumn{3}{|c|}{$\begin{array}{c}\text { Mass Fraction } \\
\text { g compound } / 2 \mathrm{~g} \text { of oil }\end{array}$} \\
\hline & & \multicolumn{3}{|r|}{ Oil sample } \\
\hline & & Distillate & Vacuum residue & SCW-treated Vacuum Residue (90 minutes) \\
\hline \multirow{25}{*}{ Alkenes } & C6 & $0.00 \mathrm{E}+00$ & $0.00 \mathrm{E}+00$ & $0.00 \mathrm{E}+00$ \\
\hline & $\mathrm{C} 7$ & $0.00 \mathrm{E}+00$ & $0.00 \mathrm{E}+00$ & 8.32E-03 \\
\hline & $\mathrm{C} 8$ & $5.17 \mathrm{E}-03$ & $0.00 \mathrm{E}+00$ & $8.88 \mathrm{E}-03$ \\
\hline & C9 & $6.55 \mathrm{E}-03$ & $0.00 \mathrm{E}+00$ & $5.68 \mathrm{E}-03$ \\
\hline & $\mathrm{C} 10$ & $7.89 \mathrm{E}-03$ & $0.00 \mathrm{E}+00$ & $6.18 \mathrm{E}-03$ \\
\hline & $\mathrm{C} 11$ & $1.01 \mathrm{E}-02$ & $0.00 \mathrm{E}+00$ & $3.51 \mathrm{E}-03$ \\
\hline & $\mathrm{C} 12$ & $1.55 \mathrm{E}-02$ & $0.00 \mathrm{E}+00$ & $3.42 \mathrm{E}-03$ \\
\hline & $\mathrm{C} 13$ & $1.52 \mathrm{E}-02$ & $0.00 \mathrm{E}+00$ & $2.53 \mathrm{E}-03$ \\
\hline & $\mathrm{C} 14$ & $1.44 \mathrm{E}-02$ & $0.00 \mathrm{E}+00$ & $1.20 \mathrm{E}-03$ \\
\hline & $\mathrm{C} 15$ & $6.69 \mathrm{E}-03$ & $0.00 \mathrm{E}+00$ & $5.53 \mathrm{E}-04$ \\
\hline & $\mathrm{C} 16$ & $3.03 \mathrm{E}-03$ & $0.00 \mathrm{E}+00$ & $1.43 \mathrm{E}-04$ \\
\hline & $\mathrm{C} 17$ & $1.45 \mathrm{E}-03$ & $0.00 \mathrm{E}+00$ & $2.83 \mathrm{E}-04$ \\
\hline & $\mathrm{C} 18$ & $1.33 \mathrm{E}-03$ & $0.00 \mathrm{E}+00$ & $2.88 \mathrm{E}-04$ \\
\hline & C19 & $8.12 \mathrm{E}-04$ & $7.50 \mathrm{E}-06$ & 4.48E-04 \\
\hline & $\mathrm{C} 20$ & $9.05 \mathrm{E}-04$ & $1.04 \mathrm{E}-05$ & $2.25 \mathrm{E}-04$ \\
\hline & $\mathrm{C} 21$ & $1.22 \mathrm{E}-03$ & $2.77 \mathrm{E}-05$ & $1.27 \mathrm{E}-04$ \\
\hline & $\mathrm{C} 22$ & 7.37E-04 & $2.46 \mathrm{E}-05$ & $6.40 \mathrm{E}-05$ \\
\hline & $\mathrm{C} 23$ & $1.83 \mathrm{E}-04$ & $2.82 \mathrm{E}-05$ & $6.24 \mathrm{E}-05$ \\
\hline & $\mathrm{C} 24$ & $2.67 \mathrm{E}-04$ & $2.84 \mathrm{E}-05$ & $1.40 \mathrm{E}-04$ \\
\hline & $\mathrm{C} 25$ & $1.51 \mathrm{E}-04$ & $1.72 \mathrm{E}-05$ & $3.74 \mathrm{E}-05$ \\
\hline & $\mathrm{C} 26$ & $0.00 \mathrm{E}+00$ & $8.41 \mathrm{E}-06$ & $3.12 \mathrm{E}-05$ \\
\hline & $\mathrm{C} 27$ & $0.00 \mathrm{E}+00$ & $1.42 \mathrm{E}-05$ & $2.84 \mathrm{E}-05$ \\
\hline & $\mathrm{C} 28$ & $0.00 \mathrm{E}+00$ & $1.05 \mathrm{E}-05$ & $6.07 \mathrm{E}-05$ \\
\hline & $\mathrm{C} 29$ & $0.00 \mathrm{E}+00$ & 8.03E-06 & $0.00 \mathrm{E}+00$ \\
\hline & $\mathrm{C} 30$ & $0.00 \mathrm{E}+00$ & $3.96 \mathrm{E}-06$ & $5.21 \mathrm{E}-05$ \\
\hline $\begin{array}{l}\text { Total GC } \\
\text { observed } \\
\text { mass } \\
\text { fraction } \\
(\mathrm{g} / \mathrm{g} \%)\end{array}$ & & $9.1 \%$ & $0.0 \%$ & $4.2 \%$ \\
\hline $\begin{array}{l}\text { Scaled } \\
\text { mass } \\
\text { fraction } \\
\text { w.r.t } \\
\text { Crude oil } \\
\end{array}$ & & $3.39 \%$ & $0.0 \%$ & $2.66 \%$ \\
\hline
\end{tabular}


10. Equations for decay of AR and formation of gas, gasoline, diesel and coke products The equations for decay of AR and formation of gas, gasoline, diesel and coke products can be recast in terms of $\mathrm{AR}_{0}$ and $\mathrm{D}_{0}$, i.e., the feedstock composition. The resulting equations are:

$$
\begin{aligned}
& K_{A}=k_{1}+k_{2}+k_{3}+k_{4} \\
& {[A R]=A R_{0} \exp \left(-K_{A} t\right)} \\
& {[\mathrm{G}]=\frac{k_{1} A R_{0}}{K_{A}}\left(1-\exp \left(-K_{A} t\right)\right)} \\
& {[\mathrm{GLN}]=\frac{k_{2} A R_{0}}{K_{A}}\left(1-\exp \left(-K_{A} t\right)\right)} \\
& {[\mathrm{D}]=\frac{k_{3} A R_{0}}{K_{A}}\left(1-\exp \left(-K_{A} t\right)\right)+D_{0}} \\
& {[\mathrm{C}]=\frac{k_{4} A R_{0}}{K_{A}}\left(1-\exp \left(-K_{A} t\right)\right)}
\end{aligned}
$$

The rate constants, $\mathrm{k}_{1}-\mathrm{k}_{4}$ were determined by numerical optimization using a MATLAB code. 